\title{
Local Acceleration of Neurofilament Transport at Nodes of Ranvier
}

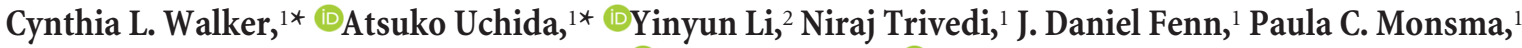 \\ Roxanne C. Lariviére, ${ }^{3}$ Jean-Pierre Julien, ${ }^{3}{ }^{-P}$ Peter Jung, ${ }^{2}$ and ${ }^{\oplus}$ Anthony Brown ${ }^{1}$ \\ ${ }^{1}$ Department of Neuroscience, Ohio State University, Columbus, Ohio 43210, ${ }^{2}$ Quantitative Biology Institute and Department of Physics and Astronomy, \\ Ohio University, Athens, Ohio 45701, and ${ }^{3}$ CERVO Brain Research Centre, Department of Psychiatry and Neuroscience, Laval University, Quebec, Quebec \\ G1J 2G3, Canada
}

Myelinated axons are constricted at nodes of Ranvier. These constrictions are important physiologically because they increase the speed of saltatory nerve conduction, but they also represent potential bottlenecks for the movement of axonally transported cargoes. One type of cargo are neurofilaments, which are abundant space-filling cytoskeletal polymers that function to increase axon caliber. Neurofilaments move bidirectionally along axons, alternating between rapid movements and prolonged pauses. Strikingly, axon constriction at nodes is accompanied by a reduction in neurofilament number that can be as much as 10-fold in the largest axons. To investigate how neurofilaments navigate these constrictions, we developed a transgenic mouse strain that expresses a photoactivatable fluorescent neurofilament protein in neurons. We used the pulse-escape fluorescence photoactivation technique to analyze neurofilament transport in mature myelinated axons of tibial nerves from male and female mice of this strain ex vivo. Fluorescent neurofilaments departed the activated region more rapidly in nodes than in flanking internodes, indicating that neurofilament transport is faster in nodes. By computational modeling, we showed that this nodal acceleration can be explained largely by a local increase in the duty cycle of neurofilament transport (i.e., the proportion of the time that the neurofilaments spend moving). We propose that this transient acceleration functions to maintain a constant neurofilament flux across nodal constrictions, much as the current increases where a river narrows its banks. In this way, neurofilaments are prevented from piling up in the flanking internodes, ensuring a stable neurofilament distribution and uniform axonal morphology across these physiologically important axonal domains.

Key words: axonal transport; myelin; myelination; neurofilament; node of Ranvier; Schwann cell

Significance Statement

Myelinated axons are constricted at nodes of Ranvier, resulting in a marked local decrease in neurofilament number. These constrictions are important physiologically because they increase the efficiency of saltatory nerve conduction, but they also represent potential bottlenecks for the axonal transport of neurofilaments, which move along axons in a rapid intermittent manner. Imaging of neurofilament transport in mature myelinated axons ex vivo reveals that neurofilament polymers navigate these nodal axonal constrictions by accelerating transiently, much as the current increases where a river narrows its banks. This local acceleration is necessary to ensure a stable axonal morphology across nodal constrictions, which may explain the vulnerability of nodes of Ranvier to neurofilament accumulations in animal models of neurotoxic neuropathies and neurodegenerative diseases.

\section{Introduction}

The sheaths of myelinated axons are interrupted periodically by short gaps called nodes of Ranvier, which are the sites of ion

Received Aug. 31, 2018; revised 0ct. 24, 2018; accepted 0ct. 26, 2018.

Author contributions: C.L.W., A.U., P.J., and A.B. wrote the paper; P.J. and A.B. designed research; C.L.W., A.U., Y.L., N.T., and J.D.F. performed research; R.C.L. and J.-P.J. contributed unpublished reagents/analytic tools; C.L.W., Y.L., P.C.M., P.J., and A.B. analyzed data.

This project was supported by collaborative National Science Foundation Grants IOS1656784 to A.B. and IOS1656765 to P.J., National Institutes of Health Grant R01 NS038526 to A.B., and National Institutes of Health Grants P30 NS104177, P30 NS045758, and S10 0D010383. J.-P.J. was supported by the Canadian Institutes of Health Research and holds a Canada Research Chair in Neurodegeneration. We thank Thomas Misgeld and Michael Coleman exchange during saltatory propagation of the nerve impulse (Salzer, 2003; Chang and Rasband, 2013; Nave and Werner, 2014). Intriguingly, axons are constricted at these sites (Hess and Young,

for helpful advice on ex vivo imaging in the early stages of this project; and George Patterson and Jennifer LippincottSchwartz for providing the paGFP plasmid.

The authors declare no competing financial interests.

${ }^{*}$ C.L.W. and A.U. contributed equally to this work.

Correspondence should be addressed to Anthony Brown at brown.2302@0su.edu.

Y. Li's present address: School of Systems Science, Beijing Normal University, Beijing, 100875, China.

N. Trivedi's present address: Department of Developmental Neurobiology, St. Jude Children's Research Hospital, Memphis, TN. 
1952; Berthold, 1978; Rydmark and Berthold, 1983; Okamura and Tsukita, 1986; Berthold, 1996) in both the central and peripheral nervous system (Hildebrand, 1971, 1993; Fabricius et al., 1993). The extent of nodal constriction is small for narrow axons but increases linearly with internodal axonal diameter, reaching threefold for the widest axons, which represents a 10 -fold reduction in axonal cross-sectional area (Rydmark, 1981; Swärd et al., 1995). Computational modeling of nerve conduction in myelinated axons has demonstrated that these constrictions are physiologically important because they reduce the nodal capacitance, thereby lowering the threshold for action potential generation (Halter and Clark, 1993). In this way, nodal constrictions minimize the internodal caliber required to achieve a given target conduction velocity and maximize the spatial and metabolic efficiency of myelinated axons (Johnson et al., 2015).

A major influence on the morphology of myelinated axons are neurofilaments, which are space-filling cytoskeletal polymers that function to expand axonal cross-sectional area (Hoffman, 1995). In large axons, neurofilaments are the most abundant structure in the cytoplasm and occupy most of the axonal volume (Friede and Samorajski, 1970; Friede et al., 1971). Electron microscopy using serial sectioning has shown that the abrupt constriction of myelinated axons at nodes of Ranvier is accompanied by an equally abrupt decrease in neurofilament number (Tsukita and Ishikawa, 1981; Reles and Friede, 1991; Price et al., 1993; Hsieh et al., 1994). For example, in one analysis of three myelinated axons, the average reduction of axonal caliber in the nodes was $82 \%$ and the average decrease in neurofilament number was $76 \%$ (Price et al., 1990). In contrast, there is no decrease in microtubule number in nodes (Tsukita and Ishikawa, 1981; Reles and Friede, 1991; Hsieh et al., 1994). Thus, most internodal microtubules extend continuously through nodes from one internode to the next, whereas most internodal neurofilaments terminate in the juxtaparanodal regions flanking each node, with only a small proportion passing through the nodes (Tsukita and Ishikawa, 1981; Reles and Friede, 1991) (Fig. 1).

In addition to their structural role in axons, neurofilaments are cargoes of axonal transport. In live-cell imaging studies of neurofilament movement in cultured nerve cells, these long flexible polymers move bidirectionally along microtubule tracks at average velocities of $\sim 0.5 \mu \mathrm{m} / \mathrm{s}$ (Brown, 2000, 2014; Wang et al., 2000). In contrast, in radioisotopic pulse-labeling studies of neurofilament movement in vivo, the average transport velocity is much slower, on the order of millimeters per day (Hoffman and Lasek, 1975; Lasek et al., 1992, 1993). Computational modeling studies suggest that this apparent discrepancy can be explained by a stop-and-go model in which the filaments alternate between rapid movements and prolonged pauses, resulting in slow transport on long time scales (Brown et al., 2005; Li et al., 2012).

The reduction in neurofilament number at nodal constrictions has consequences for the regulation of axonal morphology because it creates a potential bottleneck for axonal neurofilament traffic (Okamura and Tsukita, 1986). For example, when axons are constricted experimentally, neurofilaments pile up proximally, which leads to axonal swelling (Le Beau et al., 1988; Koehnle and Brown, 1999). However, this does not happen at nodal constrictions. Thus, a key question is as follows: how do axons maintain a stable neurofilament distribution and mor-

R.C. Lariviére's present address: Department of Neurology and Neurosurgery, Montréal Neurological Institute, McGill University, Montreal, Quebec, Canada.

https://doi.org/10.1523/JNEUROSCI.2272-18.2018

Copyright $\odot 2019$ the authors $\quad 0270-6474 / 19 / 390664-15 \$ 15.00 / 0$
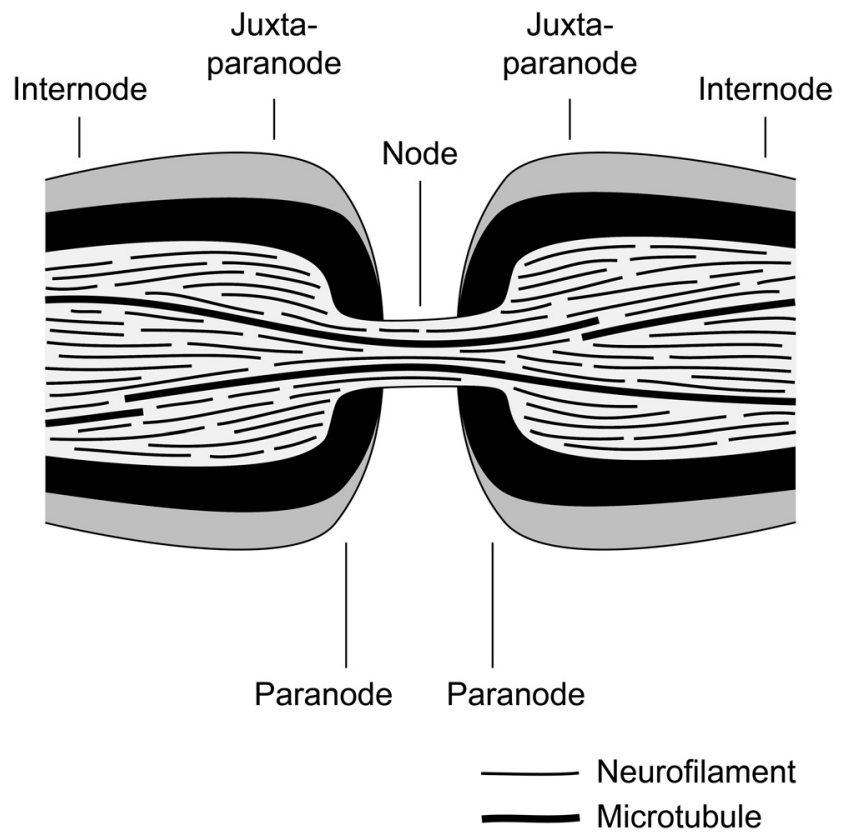

Figure 1. Diagram of neurofilament and microtubule organization across a node of Ranvier This drawing is based on electron microscopic studies of mouse and rat peripheral nerve axons (Tsukita and Ishikawa, 1981; Price et al., 1990; Reles and Friede, 1991; Perrot et al., 2007). Thin black lines indicate neurofilaments. Thick black lines indicate microtubules. The axon diameter is twofold to threefold smaller in the paranodal and nodal regions compared with the flanking internodes. Numerous neurofilaments terminate in the juxtaparanodal regions on either side of the node, resulting in a marked reduction in neurofilament number within the node. In contrast, there is no reduction in microtubule number, suggesting that single microtubules run continuously across the node from one internode to the next.

phology across nodal constrictions given that the neurofilaments are in constant flux? To address this, we developed a transgenic mouse that expresses a photoactivatable green fluorescent neurofilament fusion protein in neurons and used this mouse to investigate neurofilament transport across nodes of Ranvier in mature myelinated axons of peripheral nerves ex vivo.

\section{Materials and Methods}

Molecular cloning. The paGFP-NFM construct that was used for this study encoded paGFP connected to the N-terminus of mouse neurofilament protein M (NFM) by a 25 -amino-acid linker. It was created by subcloning mouse NFM cDNA into the paGFP-C1 vector of Patterson and Lippincott-Schwartz (Patterson and Lippincott-Schwartz, 2002) (Plasmid 11910, Addgene), as described previously (Alami et al., 2009). To prepare the vector for the generation of transgenic mice, we modified it using PCR and site-directed mutagenesis (Stratagene QuikChange XL Site-Directed Mutagenesis kit; Agilent Technologies). First, we removed HindIII and EcoRI sites in the linker, mutating the sequence caagcttcgaattct (HindIII and EcoRI sites underlined) to caagcAtcCaattct (the EcoRI site was removed for purposes not relevant to this study). These were silent changes that did not alter the amino acid sequence (QASNS). We then introduced two new HindIII sites. The first was created by changing the sequence gctagcgcta (NheI site underlined), located $5^{\prime}$ of the paGFP coding sequence and $3^{\prime}$ of the TATA box and CMV promoter, to gcAagcTTta (HindIII site underlined). The other site was created by changing the sequence acaagagtcc, located $3^{\prime}$ of the SV40 early mRNA polyadenylation (polyA) signal sequence and mRNA termination site, to acaagCTtcc (HindIII site underlined). The resulting construct contained the paGFP-NFM and 3' SV40 polyA signal sequences flanked by HindIII sites and lacking any intervening HindIII sites. Digestion of this construct with HindIII generated a $3.9 \mathrm{~kb}$ DNA fragment containing the paGFP-NFM and 3' SV40 polyA signal sequences. We then cloned this fragment into the HindIII site of a pBluescript-II-SK(+)-Thyl vector 
(Beaulieu et al., 1999), which contained the promoter, the first exon, the first intron, and the complete $5^{\prime}$ noncoding region of the second exon of the human thymus cell antigen 1 (Thyl) gene. This included the portion (intron 1) of the Thyl gene that is responsible for expression in neurons while excluding the portion responsible for expression in non-neuronal cells (Vidal et al., 1990). The resulting pBluescript-II-SK(+)-Thy1paGFP-NFM vector (see Fig. $2 A$ ) drove neuron-specific expression of the paGFP-NFM photoactivatable fluorescent fusion protein.

Transgenic mice. To generate Thyl-paGFP-NFM transgenic mice, the pBluescript-II-SK(+)-Thy1-paGFP-NFM vector was digested with NotI and PvuI. The resulting $7.6 \mathrm{~kb}$ linear DNA fragment containing the Thy1-paGFP-NFM construct was purified by agarose gel electrophoresis using a GenElute Gel Extraction Kit (MilliporeSigma) and microinjected into one-cell $(\mathrm{C} 57 \mathrm{Bl} / 6 \times \mathrm{C} 3 \mathrm{H}) \mathrm{F} 1$ mouse embryos according to standard procedures (Brinster et al., 1981). The genomic integration of the transgene was confirmed by PCR. We obtained seven transgenic founders. Crossing one of these founders with WT C57Bl/6 mice yielded five F1 transgenics, from which we established four transgenic lines that exhibited paGFP-NFM expression in the nervous system. We selected the line that expressed the highest levels (designated line 254) for this study. For the mitochondrial imaging, a heterozygous female Thy1-CFP-MitoS mouse (strain B6.CBA-Tg(Thy1-CFP/COX/8A)S2Lich/J, stock \#006617, commonly referred to as "MitoMouse") was purchased from The Jackson Laboratory and crossed with a WT male C57Bl/6 WT mouse to establish a colony in our mouse facility. Both strains of mice bred well and were maintained heterozygous by crossing with WT C57Bl/6 mice. All experiments were performed on heterozygotes.

PCR genotyping. Mice carrying the Thy1-paGFP-NFM transgene were identified by PCR genotyping of tail DNA using the following forward and reverse primers designed to amplify a $193 \mathrm{bp}$ DNA fragment within the Thyl promoter: $5^{\prime}$ atc caa tcg gtg ggt tat ca $3^{\prime}$ and $5^{\prime}$ gtg gga gag ctg gag aac tg $3^{\prime}$. For a control, we used the following forward and reverse primers designed to amplify a 497 bp DNA fragment within the kinesin-1A/ KIF5A gene: $5^{\prime}$ gat act cca agg ctg gga aca ta $3^{\prime}$ and $5^{\prime}$ tgt gga ggt cag agg tca agt 3' (Xia et al., 2003; Uchida et al., 2009). Mice carrying the Thy1$\mathrm{CFP} / \mathrm{COX} / 8 \mathrm{~A}$ transgene were identified by PCR genotyping using the following forward and reverse primers designed to amplify a $173 \mathrm{bp}$ DNA fragment within Cyan Fluorescent Protein (CFP): $5^{\prime}$ aag ttc atc tgc acc acc g $3^{\prime}$ (Jackson primer oIMR0872) and 5' tcc ttg aag aag atg gtg cg 3' (Jackson primer oIMR1416). For a control, we used the following forward and reverse primers designed to amplify a $324 \mathrm{bp}$ DNA fragment within the interleukin-2 gene: $5^{\prime}$ cta ggc cac aga att gaa aga tct $3^{\prime}$ (Jackson primer oIMR7338) and 5' gta ggt gga aat tct agc atc atc c $3^{\prime}$ (Jackson primer oIMR7339).

Tissue isolation for Western blotting. All tissue isolation was performed using heterozygous Thyl-paGFP-NFM mice and WT littermates (13 weeks of age). Freshly isolated tissues (spinal cord, cerebrum, cerebellum, lung, thymus, spleen, kidney, liver, heart, pancreas, small intestine, and testis) were chopped coarsely, frozen in liquid nitrogen, then homogenized immediately in 5 volumes of ice-cold NDSB buffer using a Teflon-glass homogenizer. Freshly isolated sciatic nerves were pooled and frozen in liquid nitrogen, crushed into a fine powder using a CryoPress frozen cell crusher (Microtec) (Uchida et al., 2001, 2004), then homogenized immediately in $1 \mathrm{ml}$ ( $\sim 30$ volumes) of ice-cold NDSB buffer using a Teflon-glass homogenizer. The NDSB buffer consisted of 1 M NDSB-201 (nondetergent sulfobetaine 201, MilliporeSigma) in 100 mм HEPES, pH 6.8, 0.5\% Triton X-100, 1 mм $\mathrm{MgCl}_{2}, 5$ mм EGTA, 1 mм DTT, PhosSTOP phosphatase inhibitor mixture (MilliporeSigma; 1 tablet/10 $\mathrm{ml}$ buffer), and a protease inhibitor mixture containing $2 \mathrm{~mm}$ 4-(2-aminoethyl) benzenesulfonyl fluoride hydrochloride, $1 \mu \mathrm{M}$ pepstatin A, $20 \mu \mathrm{M}$ leupeptin, $28 \mu \mathrm{M}$ E-64, $65 \mu \mathrm{M}$ bestatin, $135 \mu \mathrm{M}$ tosyl-L-lysylchloromethyl ketone hydrochloride, $10 \mu \mathrm{M}$ calpain inhibitor I, and $0.15 \mu \mathrm{M}$ aprotinin (all components from MilliporeSigma). The homogenates were mixed with an equal volume SDS-PAGE sample buffer $(2 \times$ concentration), sonicated, then heated in a boiling water bath for $5 \mathrm{~min}$.

Western blotting. Tissue proteins were resolved by SDS-PAGE using $6 \%$ or $7.5 \%$ polyacrylamide gels and transferred to Immobilon $\mathrm{P}^{\mathrm{SQ}}$ membranes (Millipore, $0.2 \mu \mathrm{m}$ pore size) using an electrophoretic tankblotting apparatus (Bio Craft). The membranes were blocked using Od- yssey blocking buffer (LI-COR Biosciences) for $1 \mathrm{~h}$ at room temperature. The primary antibodies were a phospho-independent mouse monoclonal antibody against NFM (RMO270, Thermo Fisher Scientific, 2000fold dilution; RRID:AB_2315286), a chicken polyclonal antibody against GFP (ab13970, Abcam, 1000-fold dilution; RRID:AB_300798), and a mouse monoclonal antibody against $\beta$-tubulin (clone TUB2.1 MilliporeSigma, 1000-fold dilution; RRID: AB_609915). The secondary antibodies were IR 800 donkey anti-chicken IgY (LI-COR Biosciences, 10,000-fold dilution) and IR 680 donkey anti-mouse IgG (LI-COR, 20,000-fold dilution). The blots were imaged using a LI-COR Odyssey Infrared Imager. Quantification was performed by measuring the fluorescence intensities of the bands on the blots using Fiji software (Schindelin et al., 2012), correcting for background by subtracting the intensity of adjacent unstained regions in between the bands within the same lane.

Isolation of neurofilaments. Neurofilaments were isolated from brain homogenates using the axonal flotation method (Shelanski et al., 1971). The brains of Thyl-paGFP-NFM mice or WT littermates (13 weeks of age) were chopped coarsely and then homogenized in 10 volumes of ice-cold MES buffer containing $0.85 \mathrm{~m}$ sucrose using a Teflon-glass homogenizer. The MES buffer consisted of $100 \mathrm{~mm}$ MES, pH 6.8, $100 \mathrm{~mm}$ $\mathrm{NaCl}, 1 \mathrm{~mm} \mathrm{MgCl}_{2}, 5 \mathrm{~mm}$ EGTA, $1 \mathrm{~mm}$ DTT, and the same phosphatase and protease inhibitor cocktails described above. The suspension was centrifuged at $300,000 \times g_{\max }$ for $1 \mathrm{~h}$ at $4^{\circ} \mathrm{C}$ and then the floating layer (containing myelinated axons) was removed and homogenized in $1 \mathrm{ml}$ of ice-cold NDSB buffer (see above). The resulting suspension was layered on top of $1.5 \mathrm{ml}$ of MES buffer containing $0.85 \mathrm{M}$ sucrose and centrifuged at $300,000 \times g_{\max }$ for $2 \mathrm{~h}$ at $4^{\circ} \mathrm{C}$. The neurofilament-rich pellet was resuspended in MES buffer without sucrose and stored frozen.

Tibial nerve dissection for live imaging. Adult male and female mice were killed using carbon dioxide inhalation followed by cervical dislocation and then positioned prone with hindpaws extended. The age of the mice ranged from 7 to 19 weeks for the pulse-escape experiments and 33-35 weeks for the mitochondrial imaging experiments. The skin was reflected, and the soleus muscle was removed to expose the tibial nerve, which originates at the knee by trifurcation of the sciatic nerve. The portion of the tibial nerve extending from the knee to the heel $(\sim 1.5 \mathrm{~cm})$ was excised and then gently desheathed in oxygenated saline under darkfield illumination and $8-16 \times$ magnification using \#5 forceps and a minutien pin. Great care was taken to minimize handling and avoid stretching the nerve as much as possible during the dissection and desheathing.

Oxygenated saline. The oxygenated saline solution contained $98 \mathrm{~mm}$ $\mathrm{NaCl}, 1 \mathrm{~mm} \mathrm{KCl}, 2 \mathrm{~mm} \mathrm{KH} \mathrm{PO}_{4}, 1 \mathrm{~mm} \mathrm{MgSO}$, $1.5 \mathrm{~mm} \mathrm{CaCl}_{2}, 5.6 \mathrm{~mm}$ D-glucose, and $24 \mathrm{~mm} \mathrm{NaHCO}_{3}$ (Breuer et al., 1987). Oxygenation was achieved by bubbling with $95 \% \mathrm{O}_{2} / 5 \% \mathrm{CO}_{2}$ for at least $30 \mathrm{~min}$ before use. The final $\mathrm{pH}$ was 7.4. To inhibit glycolysis, we substituted deoxyglucose for D-glucose and added $0.5 \mathrm{~mm}$ sodium iodoacetate (MilliporeSigma), which is an inhibitor of GAPDH (Schmidt and Dringen, 2009). Iodoacetate acts by alkylation of thiol groups so it could potentially affect the activity of other enzymes, such as molecular motors, but this was not a concern for our experiments because we simply used it to confirm that there was no contribution of passive diffusion to the pulse escape kinetics.

Microscopy and imaging. Desheathed nerves were transferred to an FCS2 closed-system temperature-controlled imaging chamber (Bioptechs), keeping track of the proximal-distal orientation. In the assembled chamber, the nerve was sandwiched between a thermally conductive microaqueduct slide on top and a \#1.5 thickness glass coverslip on bottom, separated by a $0.1-\mathrm{mm}$-thick silicone gasket. The chamber volume was $\sim 70 \mu$ l. The silicone gasket was thin enough that the nerve was squeezed gently between the top and bottom glass plates, which helped to minimize movement during perfusion. After mounting on the microscope stage, the chamber was perfused with oxygenated saline at a rate of $0.264 \mathrm{ml} / \mathrm{min}(\sim 4$ chamber volumes per minute) using a syringe pump (Orion Sage Instruments, Thermo Fisher Scientific). The saline was warmed before entering the imaging chamber using an inline solution heater (Warner Instruments). The nerves were observed by bright-field, differential interference contrast or wide-field epifluorescence microscopy on a Nikon TiE inverted microscope using a Nikon $100 \times / 1.4$ NA 
Plan Apo VC oil-immersion objective for up to $180 \mathrm{~min}$ postmortem. For bright-field imaging, we used a 0.52 NA long working distance condenser. Movies were acquired at $\sim 10$ frames per second using $100 \mathrm{~ms}$ exposures. In a limited number of experiments, we used a low-profile Warner Instruments RC-30HV closed-system temperature-controlled imaging chamber and a 1.5 NA oil-immersion condenser to obtain better resolution. For fluorescence imaging, we attenuated the epi-illumination from the mercury arc lamp fourfold using neutral density filters. To image the Thy1-paGFP-NFM nerves, we used an ET-GFP filter set (filter set \#49002, Chroma Technology). To image the Thy1-CFP-MitoS nerves, we used an ET-ECFP filter set (filter set \#49001, Chroma Technology). In all cases, we avoided areas that were within $\sim 1 \mathrm{~mm}$ of the cut ends (5 FOVs through the eyepieces). To obtain the best image quality, we focused on axons that were located on the bottom surface of the nerve, immediately adjacent to the glass coverslip. Thus, all our analyses were confined to axons at the periphery of the nerve. Images were acquired using a CoolSNAP HQ cooled CCD camera (Photometrics) and MetaMorph software (Molecular Devices). The perfusion pump was stopped temporarily during imaging to maximize the stability of the preparation during image acquisition. Freshly dissected brains were sliced manually using a razor blade, lightly fixed in $4 \%$ formaldehyde in PBS containing $1 \%$ sucrose, and then imaged using a MZ16FA fluorescence stereomicroscope (Leica Microsystems) with a violet filter and a $1.0 \times$ Plan Apo objective. At this magnification, the paGFP was excited by the violet light without being photoconverted.

Analysis of mitochondrial movement. To analyze mitochondrial movement in tibial nerves from adult Thy1-mitoS-CFP transgenic mice (Misgeld et al., 2007), we acquired time-lapse movies of 2 min duration at $0.82 \mathrm{~s}$ time intervals using $0.5 \mathrm{~s}$ exposures ( $\sim 147$ frames per movie). Approximately $30 \%$ of the axons expressed CFP, corresponding to $\sim 4$ axons per FOV. For each axon that contained fluorescent mitochondria, we drew three lines perpendicular to the long axis of the axon, one midway along its length and the others $\sim 13 \mu \mathrm{m}$ apart on either side. We then stepped through the videos manually frame-by-frame and counted the number of mitochondria that crossed each line in either the anterograde or retrograde direction and averaged the numbers for the three lines for each axon.

Photoactivation. paGFP-NFM was photoactivated in nodes and internodes by illumination with violet light for $6 \mathrm{~s}$ using a Mosaic Digital Diaphragm multi-mirror array device (Andor Technology) equipped with a secondary mercury arc lamp light source (Olympus America) and controlled using the Targeted Illumination drop-in in the MetaMorph software. Light from the Nikon microscope mercury arc lamp and the Mosaic Digital Diaphragm was introduced into the epi-illumination light path using a $450 \mathrm{~nm}$ short-pass dichroic mirror that transmits in the violet and reflects in the blue, and was directed to the specimen using a $495 \mathrm{~nm}$ long-pass dichroic mirror (Chroma Technology) in the filter turret. For subsequent observation and imaging of the activated green fluorescence, we used an ET-GFP filter cube.

Pulse-escape experiments. A single node of Ranvier was located and centered in the FOV. Typically, we found approximately a dozen suitable nodes in each preparation. To confirm the health of the preparation, we routinely acquired movies under bright-field illumination using streaming acquisition. We were only able to detect the movement of the most refractile organelles using this approach, but we used this as an index of the overall health of the preparation. To reduce background autofluorescence before photoactivation, we photobleached the entire field by exposing it to blue light for 10-20 s using the ET-GFP fluorescence filter cube. Then we focused on the axon of interest under bright-field illumination, acquired a preactivation image of the paGFP fluorescence using the ET-GFP fluorescence filter cube, and used the Mosaic Digital Diaphragm to photoactivate the fluorescence in the node. The activated region was $5.5 \mu \mathrm{m}$ ( 85 pixels) in length and wide enough to encompass the entire width of the axon. We acquired an image of the paGFP fluorescence immediately after activation and then at intervals over a period of 30 or $60 \mathrm{~min}$, refocusing under bright-field before each image acquisition. All exposures were $1 \mathrm{~s}$ in duration. All photobleaching and photoactivation were performed using the maximum unattenuated illumination from the mercury arc lamp of the Mosaic Digital Dia- phragm, whereas all imaging of the activated fluorescence was performed using a fourfold attenuation of the mercury arc lamp of the Nikon microscope. After completing the pulse-escape run in the node, we moved into one of the flanking internodes and repeated the entire procedure there using an activated region of identical length. To ensure that the fluorescent neurofilaments leaving the nodal activated region did not contribute to the fluorescence of the internodal activated region, we spaced the internodal region at least $250 \mu \mathrm{m}$ from the nodal region. For pulse-escape experiments in the presence of inhibitors of glycolysis, axons were activated after $20-30 \mathrm{~min}$ in the inhibitors, which is the time that it took to observe inhibition of organelle movement.

Measurement of fluorescence intensities. The intensity of the activated paGFP fluorescence was measured using MetaMorph software. For each pulse-escape time series, a rectangular ROI was drawn manually around the photoactivated region in the image acquired immediately after activation and the fluorescence intensity in this region was measured for each time point in the time series, as well as in the preactivation image. To correct for background fluorescence, we subtracted the intensity in the ROI of the preactivation image from all subsequent postactivation images. The resulting background-corrected intensities were then corrected for photobleaching. To calibrate the rate of photobleaching, we acquired images of the photoactivated paGFP fluorescence in rapid succession and then quantified the fluorescence decay. The photobleaching kinetics were exponential, with a loss of $0.5 \%$ per second of exposure using fourfold attenuation of the exciting light (data not shown). The data were expressed as intensity per linear pixel by dividing the measured intensity by the axial length of the ROI.

Measurement of axonal caliber and relative neurofilament content. After both the node and internode pulse-escape runs were complete, the node was recentered in the FOV and the entire length of the axon within the FOV was activated and imaged to quantify the morphology and relative neurofilament content in the paranodal and juxtaparanodal regions. Axon diameter was measured using the Calipers tool in the MetaMorph software. Cross-sectional area was calculated from the diameter assuming that the axons were cylindrical in shape. The relative neurofilament content of the nodal, paranodal, juxtaparanodal, and internodal regions was calculated based on the relative fluorescence intensities, quantified as described above.

Experimental design and statistical analysis. All experiments and observations were repeated to ensure reproducibility. Both male and female mice were used, and no gender-specific differences were observed. The fluorescence images of the WT and Thyl-paGFP-NFM mouse brains in Figure 2 were representative of independent observations on the brains of five different pairs of mice. The Western blots and CBBR-stained gels in Figure 3 were each representative of the results obtained from at least three independent experiments (i.e., at least three pairs of age-matched transgenic and WT mice), with the exception of the Western blot in Figure $3 E$, which was representative of the results obtained from two independent experiments (i.e., two pairs of age-matched WT and transgenic mice). The linear regression analysis in Figure 5 was performed in Kaleidagraph (Synergy Software). Statistical analysis of the pulse-escape kinetics in Figures 8 and 9 was performed in Microsoft Excel at each time point using a two-tailed $t$ test for paired samples or a two-tailed $t$ test for independent samples with unequal variances, as indicated in the figure legends. Sample sizes and exact $p$ values are reported in the figure legends.

Mathematical modeling. Assuming a stable distribution of neurofilament content $c$ across the nodes of Ranvier (i.e., a content that does not change with time), the flux $j$ of neurofilaments across the nodes must also be a constant. If it was not, the influx would not match the efflux and consequently there would be an accumulation or a depletion of neurofilaments with time. This can be expressed simply as an equation of continuity for neurofilament flow, that is:

$$
c_{\text {node }} v_{\text {node }}=c_{\text {internode }} v_{\text {internode }}
$$

where $v_{\text {node }}$ and $v_{\text {internode }}$ denote the average neurofilament velocities in the node and internode, respectively, and $c_{\text {node }}$ and $c_{\text {internode }}$ denote the corresponding neurofilament content. Thus, $v_{\text {node }} / v_{\text {internode }}=c_{\text {internode }} /$ 
$c_{\text {node }}$ can be determined experimentally as the ratio of the neurofilament fluorescence intensity in the internode to that in the node.

To extract the values of the average neurofilament velocities $v_{\text {node }}$ and $v_{\text {internode }}$ in nodes and internodes, including the corresponding kinetic rate constants, we simulated neurofilament movement in pulse-escape experiments using computational modeling and determined the kinetic parameters that resulted in a best fit of the model to the experimental data. The method is described in detail in a previous publication (Li et al., 2014). Briefly, we used a cargo-based "stop-and-go" transport model in which each neurofilament moves anterogradely or retrogradely in bursts of rapid intermittent movement interrupted by long pauses (Jung and Brown, 2009). Such kinetics are captured in a mathematical model with six states: anterograde and retrograde moving states "a" and " $r$ " (in which the neurofilaments move with anterograde and retrograde velocities $v_{\mathrm{a}}$ and $v_{\mathrm{r}}$ ), short-term pausing states "a0" and "r0" (in which the neurofilaments pause on a time scale of seconds to minutes), and off-track states "ap" and "rp" (in which the neurofilaments pause persistently on a time scale of hours). Mathematically, this model is described by the following set of partial differential equations:

$$
\begin{gathered}
\frac{\partial \rho_{\mathrm{a}}}{\partial t}=-v_{\mathrm{a}} \frac{\partial \rho_{\mathrm{a}}}{\partial x}-\gamma_{10} \rho_{\mathrm{a}}+\gamma_{01} \rho_{\mathrm{a} 0} \\
\frac{\partial \rho_{\mathrm{r}}}{\partial t}=-v_{\mathrm{r}} \frac{\partial \rho_{\mathrm{r}}}{\partial x}-\gamma_{10} \rho_{\mathrm{r}}+\gamma_{01} \rho_{\mathrm{r} 0} \\
\frac{\partial \rho_{\mathrm{a} 0}}{\partial t}=-\left(\gamma_{01}+\gamma_{\mathrm{ar}}+\gamma_{\mathrm{off}}\right) \rho_{\mathrm{a} 0}+\gamma_{10} \rho_{\mathrm{a}}+\gamma_{\mathrm{ra}} \rho_{\mathrm{r} 0}+\gamma_{\mathrm{on}} \rho_{\mathrm{ap}} \\
\frac{\partial \rho_{\mathrm{r} 0}}{\partial t}=-\left(\gamma_{01}+\gamma_{\mathrm{ra}}+\gamma_{\mathrm{off}}\right) \rho_{\mathrm{r} 0}+\gamma_{10} \rho_{\mathrm{r}}+\gamma_{\mathrm{ar}} \rho_{\mathrm{a} 0}+\gamma_{\mathrm{on}} \rho_{\mathrm{rp}} \\
\frac{\partial \rho_{\mathrm{ap}}}{\partial t}=-\left(\gamma_{\mathrm{on}}+\gamma_{\mathrm{ar}}\right) \rho_{\mathrm{ap}}+\gamma_{\mathrm{off}} \rho_{\mathrm{a} 0}+\gamma_{\mathrm{ra}} \rho_{\mathrm{rp}} \\
\frac{\partial \rho_{\mathrm{rp}}}{\partial t}=-\left(\gamma_{\mathrm{on}}+\gamma_{\mathrm{ra}}\right) \rho_{\mathrm{rp}}+\gamma_{\mathrm{off}} \rho_{\mathrm{r} 0}+\gamma_{\mathrm{ar}} \rho_{\mathrm{ap}},
\end{gathered}
$$

where $\rho_{\mathrm{a}}, \rho_{\mathrm{a} 0}, \rho_{\mathrm{ap}}, \rho_{\mathrm{r}}, \rho_{\mathrm{r} 0}, \rho_{\mathrm{rp}}$ denote the densities of the neurofilaments in the kinetic states, $\gamma_{01}, \gamma_{10}, \gamma_{\text {off }}, \gamma_{\text {on }}, \gamma_{\mathrm{ar}}$ and $\gamma_{\mathrm{ra}}$ are the rate constants that described the transitions between these states, $x$ denotes distance along the axon, and $v_{\mathrm{a}}$ and $v_{\mathrm{r}}$ denote the anterograde and retrograde velocities of the moving filaments. A schematic of the states and rate constants is shown in Figure $11 B$. We have shown previously that this model successfully mimics the movement of single neurofilaments on a time scale of seconds or minutes (Brown et al., 2005) as well as the transport of large ensembles of neurofilaments on a time scale of weeks or months (Jung and Brown, 2009).

The reversal rates are by far the smallest of the rates and have been estimated to be on the order of $10^{-5} / \mathrm{s}$ (Jung and Brown, 2009). This means that, within the short duration of our pulse-escape experiments, reversals can be neglected. For anterograde and retrograde velocities, we assumed $v_{\mathrm{a}}=0.5 \mu \mathrm{m} / \mathrm{s}$ and $v_{\mathrm{r}}=-0.5 \mu \mathrm{m} / \mathrm{s}$, which fall within the range of our published measurements in cultured neurons (Wang et al., 2000; Wang and Brown, 2001; Uchida and Brown, 2004; Alami et al., 2009; Uchida et al., 2009).

Activating the neurofilaments in an axonal window of length $a$, the model predicts the decay of fluorescence in that window due to the departure of neurofilaments. At short times (i.e., immediately after photo-activation), the relative fluorescence within the activation window $Q(t) / Q(0)$ decays linearly with time (Li et al., 2014), as follows:

$$
\frac{Q(t)}{Q(0)}=1-\frac{v_{a}}{a} \frac{1}{1+q_{1}\left(1+q_{2}\right)} t \equiv 1-\alpha t
$$

where $Q(t)$ is the fluorescence intensity at time $t, Q(0)$ is the fluorescence intensity immediately after activation, and $\alpha$ is the initial slope of the decay curve, which is proportional to the average neurofilament velocity $\bar{v}$ given by the following:
A

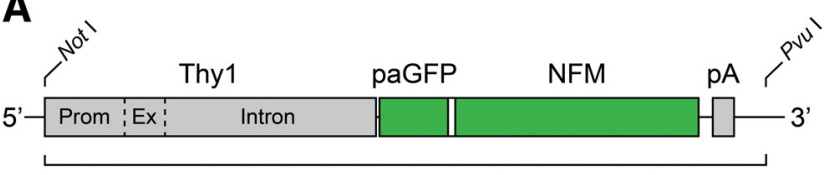

$7.6 \mathrm{~kb}$

\section{B}

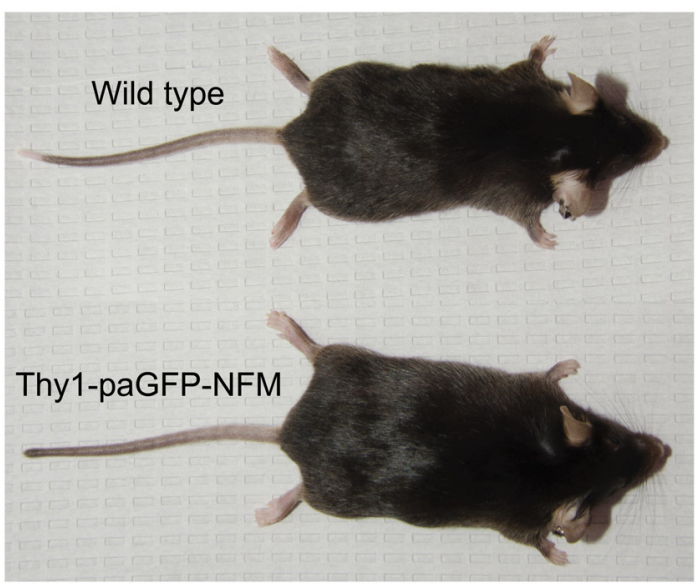

C
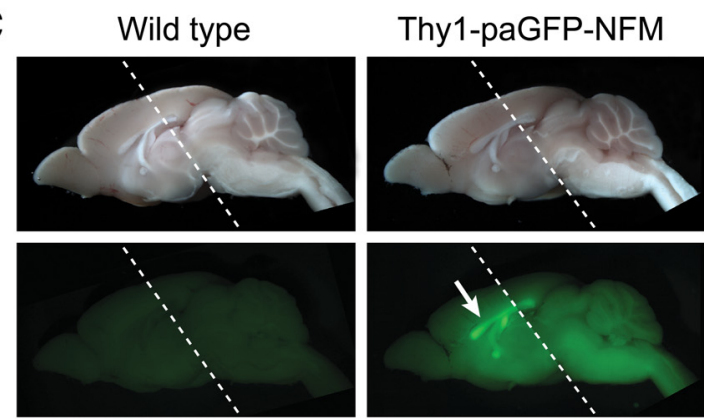

Figure 2. The Thy1-paGFP-NFM transgenic mouse. $\boldsymbol{A}$, The transgene construct consisted of the promoter (837 bp), first exon (424 bp), first intron (2183 bp), and complete 5' noncoding region of the second exon (23 bp), of the human thymus cell antigen 1 (Thy1) gene upstream of the cDNA for the paGFP-NFM fusion protein and 3' SV40 polyadenylation signal sequences (pA). Digestion with Notl and Pvul restriction endonucleases generated a $7.6 \mathrm{~kb}$ linear DNA fragment that was used to generate the transgenic mice. $\boldsymbol{B}$, WT and heterozygous Thy1-paGFP-NFM transgenic male sibling mice at 24 weeks of age. $C$, Brains of WT and heterozygous Thy1-paGFPNFM transgenic male sibling mice at 12 weeks of age, mid sagittal section. The images were acquired in the same imaging session using identical illumination and exposure settings, and the fluorescence intensities were scaled identically to allow direct comparison. Top, Bright-field illumination. Bottom, Epifluorescence illumination using violet light. Each panel is a montage of two images spliced together along the diagonal dashed line. Note the bright paGFP fluorescence in the anterior commissure, fornix, and corpus callosum (arrow), and fainter diffuse fluorescence in other regions, including the cerebral cortex, cerebellar white matter, and brain stem.

$$
\bar{v}=\frac{v_{\mathrm{a}}}{\left(1+q_{1}\left(1+q_{2}\right)\right)} \frac{\left(1-q_{3}\right)}{\left(1+q_{3}\right)}
$$

and inversely proportional to the length of the activation window $a$, with the following:

$$
q_{1}=\gamma_{10} / \gamma_{01}, q_{2}=\gamma_{\mathrm{off}} / \gamma_{\mathrm{on}}, q_{3}=\gamma_{\mathrm{ar}} / \gamma_{\mathrm{ra}}
$$

At long times, the fluorescence decays exponentially as follows:

$$
Q(t)=Q_{\infty} \exp \left(-\gamma_{\mathrm{d}} \mathrm{t}\right)
$$

where the decay constant $\gamma_{\mathrm{d}}$ and $Q_{\infty}$ can be obtained by an exponential fit of the fluorescence decay at long times. Given a set of values for $\gamma_{10}$ and 
A

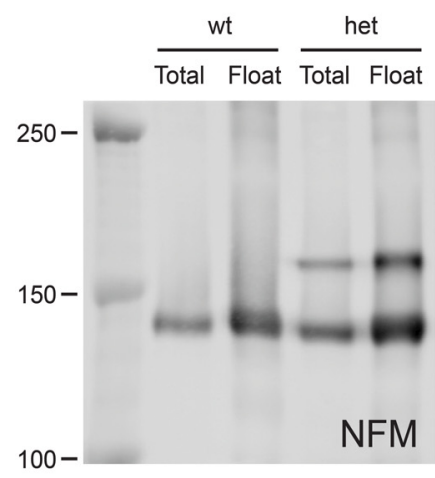

B Brain neurofilaments
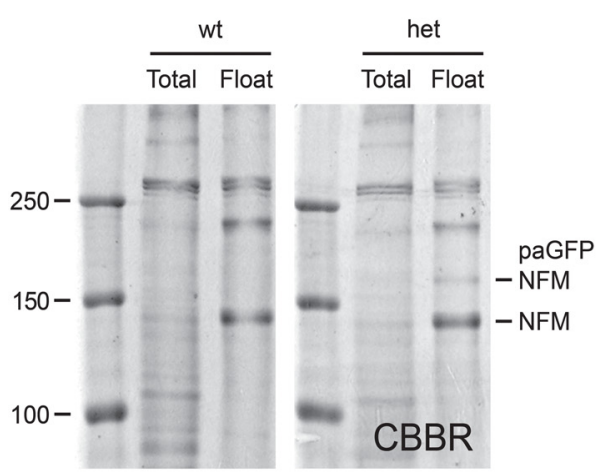

D Expression in sciatic nerve

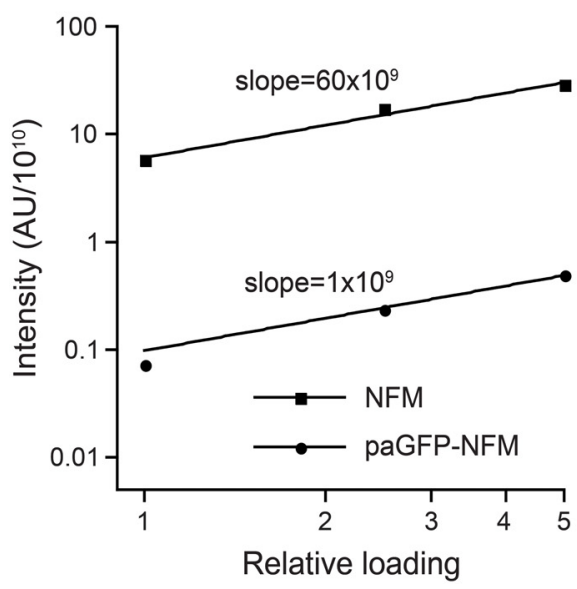

Brain neurofilaments
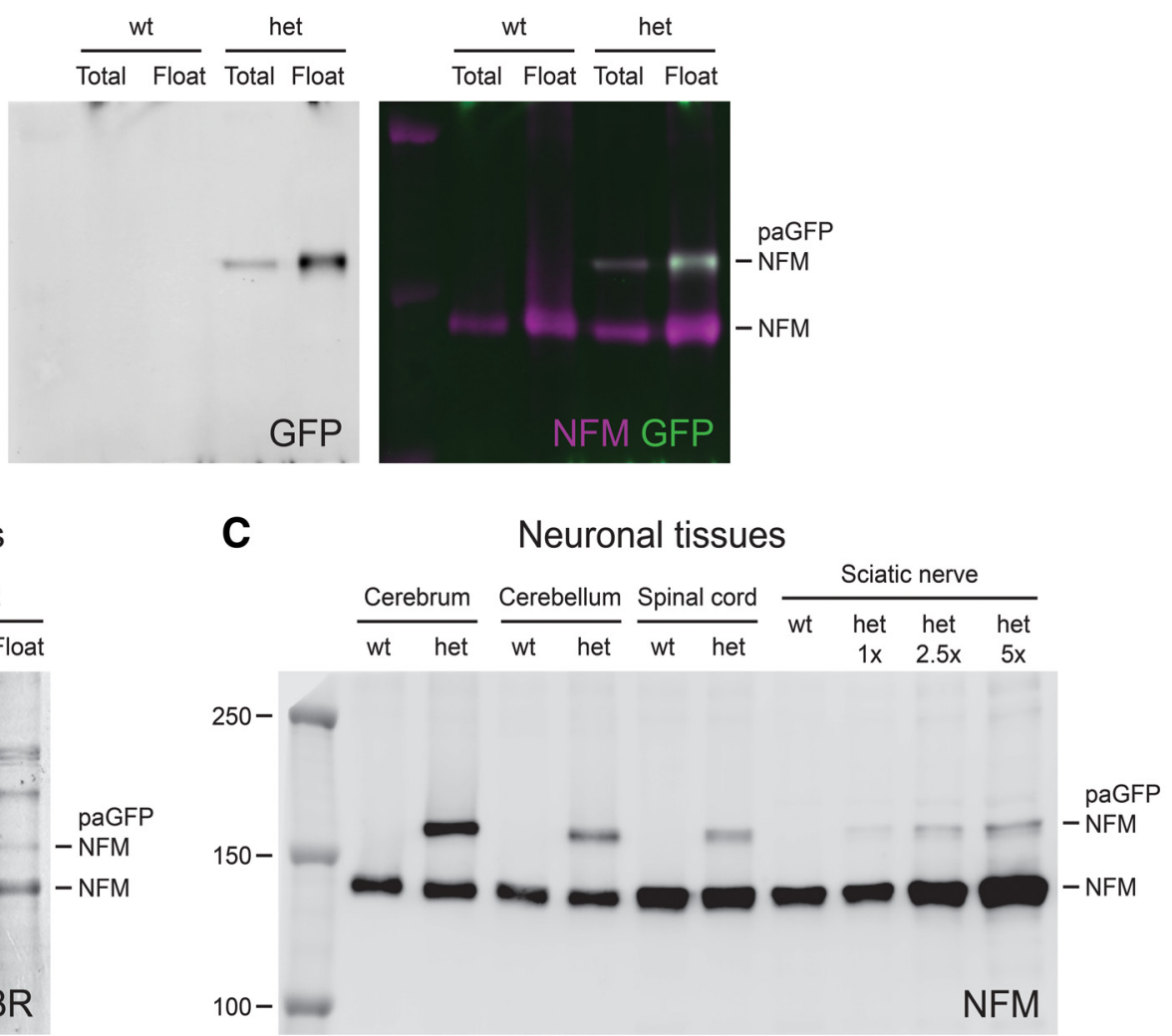

$\mathbf{E}$

Non-neuronal tissues

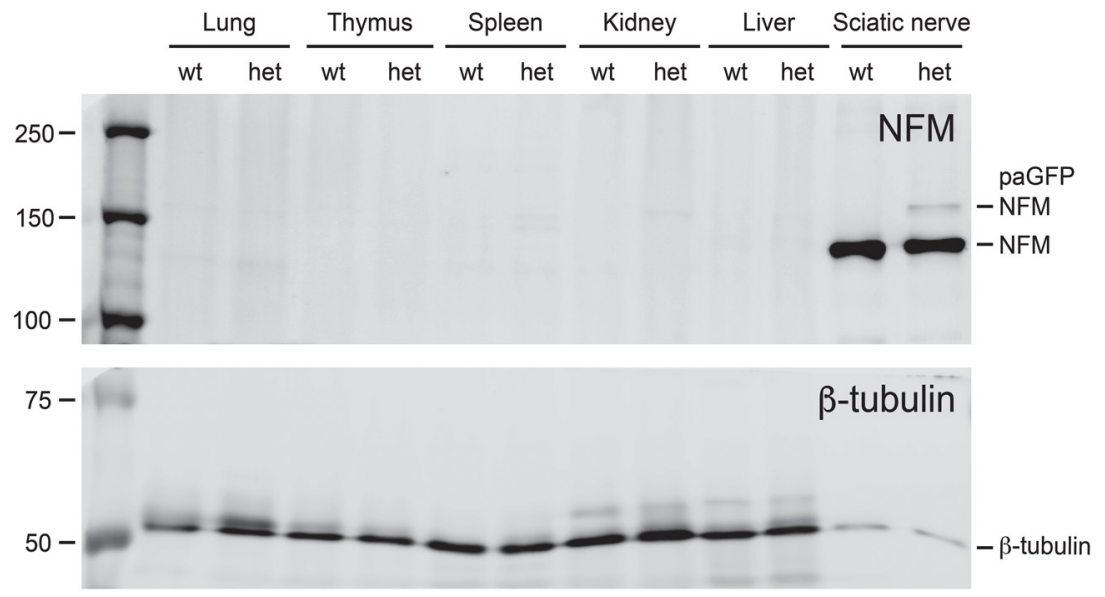

Figure 3. Expression of the paGFP-NFM fusion protein. $A$, Western blotting of total protein from brain ("Total") and from a brain fraction enriched for neurofilaments from myelinated axons using the axonal flotation method ("Float"). Staining with NFM antibody revealed a band corresponding to NFM in WT mice ("wt") and two bands corresponding to endogenous NFM and the paGFP-NFM fusion protein in age-matched heterozygous Thy1-paGFP-NFM mice ("het"). Double-staining with GFP antibody confirmed that the upper band was the fusion protein. Color overlay: Magenta represents NFM. Green represents GFP. White represents overlap. Pre-stained markers (only visible on NFM blot): 100, 150 and $250 \mathrm{kDa}$. B, Coomassie (CBBR) protein stain of a gel obtained by SDS-PAGE of the protein samples in $A$. The paGFP-NFM fusion protein can be detected in the heterozygous transgenic mice. Pre-stained markers: 100,150 , and 250 kDa. C, Western blotting of total protein extracted from various neuronal tissues of age-matched WT and heterozygous Thy1-paGFP-NFM mice. The expression of the paGFP-NFM fusion protein was highest in the cerebrum and lowest in the sciatic nerve. Three loadings of the sciatic nerve sample are shown $(1 \times, 2.5 \times$, and $5 \times)$ to facilitate detection. Pre-stained markers: 100, 150, and 250 kDa. D, Quantification of the relative intensity of NFM and paGFP-NFM in sciatic nerve for the three loadings shown in $C(\log -\log$ plot). The curves are linear with respect to relative loading, yielding a ratio of 1:60 paGFP-NFM: NFM. This indicates that in sciatic nerve the paGFP-NFM protein is expressed at $1.6 \%$ of the level of endogenous NFM protein. $\boldsymbol{E}$, Western blotting of total protein extracted from sciatic nerve and various non-neuronal tissues. The membrane was cut in half. The top half was stained for NFM, and the bottom half was stained for $\beta$-tubulin as a loading control. The loading was equivalent in wet weight for each tissue, except for the sciatic nerve, which was diluted 10-fold relative to the other samples. Pre-stained markers (visible on both blots): 50, 75, 100, 150, and 250 kDa. 


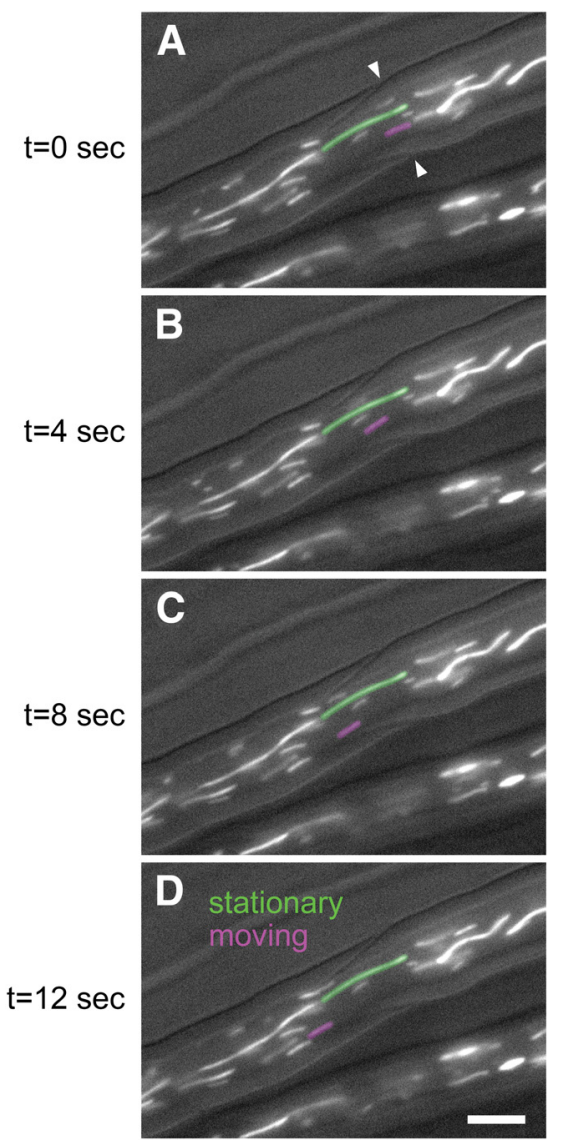

Figure 4. Mitochondrial movement in tibial nerve explants. $\boldsymbol{A}-\boldsymbol{D}$, Excerpts from a timelapse movie of mitochondria in myelinated axons of tibial nerve excised from an adult Thy1CFP-MitoS transgenic mouse and maintained on the microscope stage with constant perfusion of oxygenated saline. This FOV contains two myelinated axons expressing cyan fluorescent mitochondria. Some of the mitochondria were stationary during the period of observation (e.g., the mitochondrion highlighted in green) and others were motile (e.g., the mitochondrion highlighted in magenta). In general, the motile mitochondria tended to be shorter in length. A Schmidt-Lanterman cleft is visible in the myelin sheath in the center of the FOV ( $\boldsymbol{A}$, white arrowheads). Scale bar, $5 \mu \mathrm{m}$.

$\gamma_{01}$ and hence $q_{1}=\gamma_{10} / \gamma_{01}$, the value of the initial slope $\alpha$ constrains the ratio $q_{2}=\gamma_{\text {off }} / \gamma_{\text {on }}$ (see Eq. 3), and the value of $\gamma_{\mathrm{d}}$ subsequently determines $\gamma_{\text {on }}$ and $\gamma_{\text {off }}$ as a function of $\gamma_{10}$ and $\gamma_{01}$. To match the experimental data, we scanned the entire $2 \mathrm{D}$ plane of values of $\gamma_{10}$ and $\gamma_{01}$ to determine the best fit of the entire decay curve by the model. To find simultaneously the best fit to both fluorescent decay curves obtained from the nodal and internodal pulse-escape experiments, we allowed each individual slope $\alpha_{\text {node }}$ and $\alpha_{\text {internode }}$ to vary under the constraint $\alpha_{\text {node }} / \alpha_{\text {internode }}=\bar{v}_{\text {node }} / \bar{v}_{\text {internode }}=7.6$ and determined the set of rate constants for both fluorescence decay curves that minimized the sum of the errors of each curve.

The fraction of the time spent in the various kinetic states and the average pause duration and run times were calculated from the rate constants using algebraic expressions derived in Jung and Brown (2009) and Li et al. (2014), as follows:

$$
p_{\text {on }}=\frac{1+q_{1}}{1+q_{1}\left(1+q_{2}\right)}, p_{\text {off }}=\frac{q_{1} q_{2}}{1+q_{1}\left(1+q_{2}\right)}, p_{\text {run }}=\frac{1}{1+q_{1}\left(1+q_{2}\right)}
$$

$$
\left\langle T_{\text {on }}\right\rangle=\frac{1}{\gamma_{01}+\gamma_{\text {off }}},\left\langle\mathrm{T}_{\text {off }}\right\rangle=\frac{1}{\gamma_{\text {on }}},\left\langle\mathrm{T}_{\text {run }}\right\rangle=\frac{1}{\gamma_{10}},
$$

where $p_{\text {on }}, p_{\text {off }}$, and $p_{\text {run }}$ are the fractions of time spent pausing on and off track and moving, respectively, and $\left\langle T_{\text {on }}\right\rangle,\left\langle T_{\text {off }}\right\rangle$, and $\left\langle T_{\text {run }}\right\rangle$ are the aver-
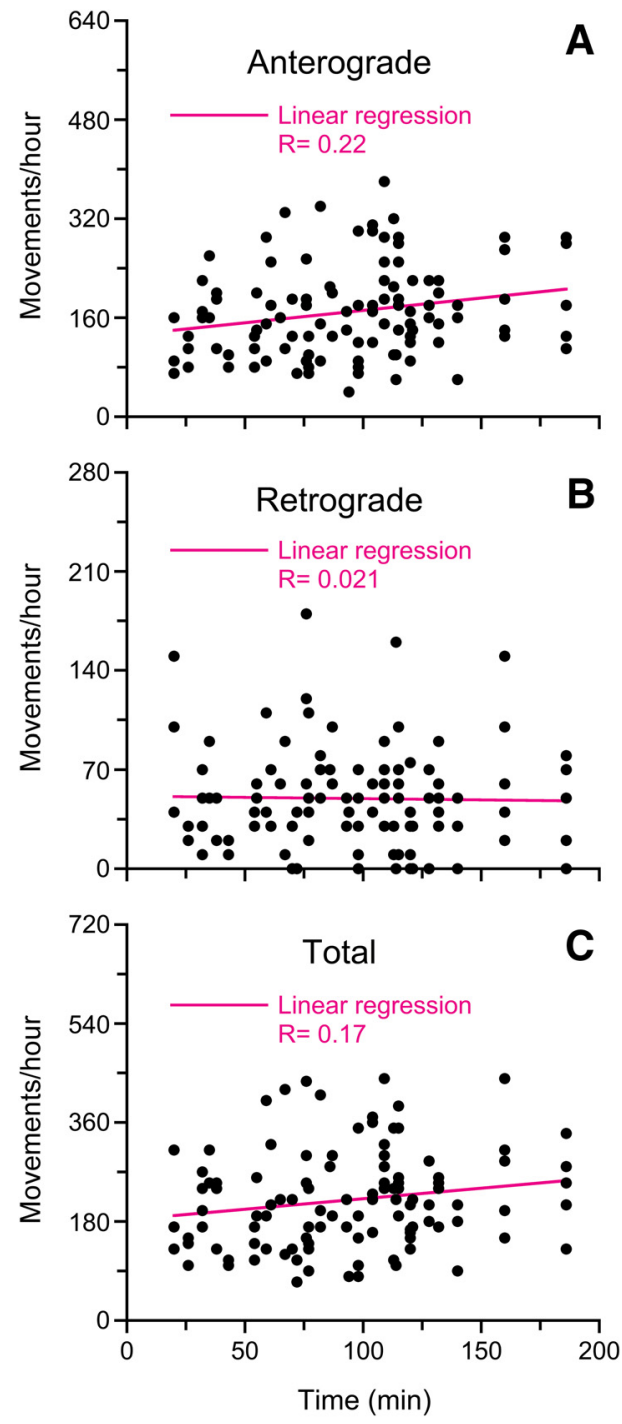

Figure 5. Quantification of mitochondrial flux in tibial nerve explants. Scatter plots of mitochondrial motility in myelinated axons of tibial nerves excised from adult Thy1-CFP-Mitos transgenic mice (33-35 weeks of age) and maintained on the microscope stage with constant perfusion of oxygenated saline. For each axon, we drew three lines perpendicular to the long axis of the axon and spaced $\sim 13 \mu \mathrm{m}$ apart and then counted the number of mitochondria that crossed these lines in a 2 min time period. Each data point represents the average flux for a single axon. In total, we analyzed 111 axons in 38 movies from the tibial nerves of 3 different mice. Total number of motile mitochondria counted $=2391$. $\boldsymbol{A}$, Anterograde movements. $\boldsymbol{B}$, Retrograde movements. $\boldsymbol{C}$, Total movements (anterograde plus retrograde). Linear regression analysis revealed no decline in the motility over a $3 \mathrm{~h}$ period ( $20-186$ min postmortem).

age durations of the on-track pauses, off-track pauses and runs, respectively.

\section{Results}

Thy1-paGFP-NFM transgenic mice

Heterozygous Thyl-paGFP-NFM mice appeared healthy, were similar in size and weight to WT siblings, and bred normally (Fig. $2 B)$. The animals were genotyped by PCR using primers that amplified a portion of the GFP coding sequence. Lightly fixed and sliced brains from transgenic mice exhibited green fluorescence under violet illumination compared with WT siblings. The fluorescence was brightest in the axon tracts of the anterior commissure, fornix, and corpus callosum, with fainter diffuse fluorescence in other brain regions, including the cerebral cortex, cerebellar white matter, and brain stem (Fig. 2C) as well as in the 
optic nerve and tract (data not shown). This is consistent with an enrichment of the paGFP-NFM fusion protein in axons.

To further characterize the expression of the transgene, we performed Western blotting on total protein extracts and enriched neurofilament preparations from tissues of age-matched WT and heterozygous Thyl-paGFP-NFM transgenic mice. Antibodies specific for NFM detected a prominent band in neuronal tissues with an apparent molecular weight of $\sim 140,000$, which corresponds to endogenous NFM. In neuronal tissues from heterozygous transgenic mice, we also detected a second band with an apparent molecular weight of $\sim 170,000$. This is consistent with the expected molecular weight of the paGFP-NFM fusion protein $\left(\mathrm{M}_{\mathrm{w}} 140,000 \mathrm{NFM}+\mathrm{M}_{\mathrm{w}} 27,000 \mathrm{paGFP}+\mathrm{M}_{\mathrm{w}} 3000\right.$ linker). Double-staining with an antibody specific for GFP confirmed that this band was the paGFP-NFM fusion protein (Fig. $3 A)$. The fusion protein was expressed in cerebrum, cerebellum, spinal cord, and sciatic nerve (Fig. $3 C$ ) but absent in lung, thymus, spleen, kidney, and liver (Fig. 3E). The fusion protein was also absent in heart, pancreas, small intestine, and testis (data not shown). Quantification of the relative intensities of the NFM and paGFP-NFM bands on the NFM blots revealed that the transgene was expressed at $94 \%$ of the endogenous protein level in cerebrum, $33 \%$ in cerebellum, $7 \%$ in spinal cord, and $1.6 \%$ in sciatic nerve. The quantification for the sciatic nerve is shown in Figure $3 D$. The expression level in brain was high enough to detect by Coomassie protein staining (Fig. 3B). Thus, the transgene is expressed in a neuron-specific manner, with relatively high expression in brain and relatively low expression in peripheral nerve.

\section{Viability of tibial nerve axons ex vivo}

Previous work has shown that the axonal transport of membranous organelles can be imaged in myelinated axons of freshly isolated peripheral nerves (Breuer et al., 1987; Smith, 1989; Smith and Bisby, 1993; Viancour and Kreiter, 1993; Milde et al., 2015). To do this, we excised 10-15 mm segments of the tibial nerve from adult mice and maintained the nerves on the microscope stage in a closed-bath imaging chamber with constant perfusion of oxygenated saline as described in Materials and Methods. After severing, the cut ends of axons constrict and the membrane reseals by a $\mathrm{Ca}^{2+}$ and SNARE-dependent vesicular fusion repair mechanism (Bloom and Morgan, 2011; Spaeth et al., 2012), which permits the axons to remain viable for several hours. Myelinated axons were readily apparent using bright-field microscopy due to the refractility of the myelin sheaths. To obtain the best image quality, we confined our analyses to axons lying at the surface of the nerve against the glass coverslip. While tibial nerves contain both motor and sensory axons, previous studies have shown that the vast majority of the superficial large axons are motor axons, so it is likely that most of the axons that we analyzed are motor axons (Marinkovic et al., 2012).

To confirm the viability of the preparation, we imaged mitochondrial motility in tibial nerves from adult Thy1-CFP-mitoS transgenic mice (Misgeld et al., 2007; Gilley et al., 2012; Marinkovic et al., 2012; Mar et al., 2014). These mice express the mitochondrial targeting signal of human cytochrome $c$ oxidase subunit $8 \mathrm{~A}$ fused to the $\mathrm{N}$ terminus of CFP under the control of neuron-specific elements of the mouse Thyl promoter. This results in cyan fluorescent mitochondria in a broad range of neurons, including $\sim 30 \%$ of the superficial myelinated axons in the tibial nerve. Figure 4 shows excerpts of a representative timelapse movie showing moving and stationary mitochondria. Regression analysis revealed no decline in either anterograde or retrograde mitochondrial motility over a $180 \mathrm{~min}$ period (Fig. 5).

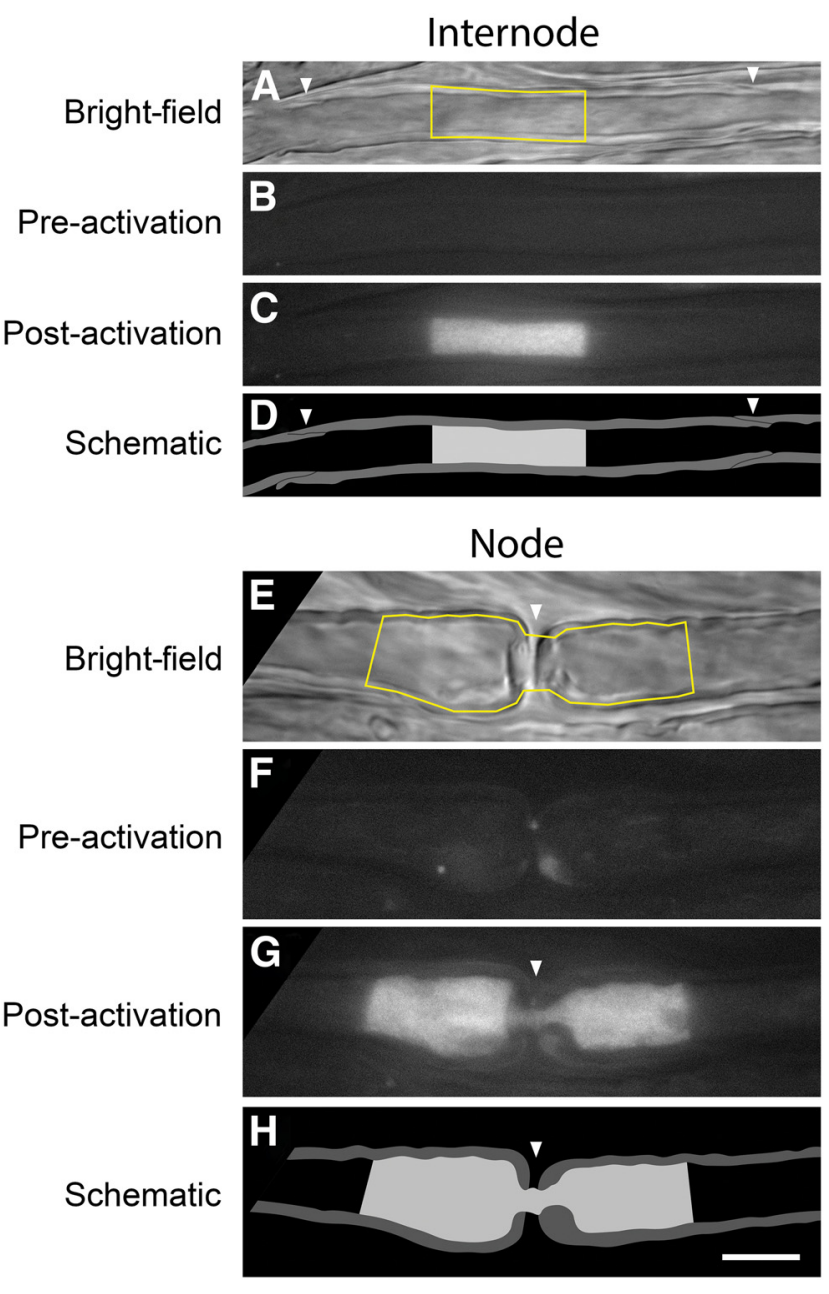

Figure 6. Photoactivation of nodal and internodal regions of axons in tibial nerve. $A-D, A n$ internode. $\boldsymbol{E}-\boldsymbol{H}, \mathrm{A}$ node of Ranvier. $\boldsymbol{A}, \boldsymbol{E}$, Bright-field images. Yellow region represents the area that was activated. $\boldsymbol{B}, \boldsymbol{F}$, Images of the paGFP fluorescence before photoactivation. $\boldsymbol{C}, \boldsymbol{G}$, Images of the paGFP fluorescence immediately after activation. $\boldsymbol{D}, \boldsymbol{H}$, Schematic diagrams showing the activated axonal regions (light gray) and the myelin sheath morphology (dark gray). White arrowheads indicate the $S$ chmidt-Lanterman incisures in $\boldsymbol{A}$ and $\boldsymbol{D}$ and the dramatic and abrupt constriction of the axon in the nodal and paranodal regions in $\boldsymbol{E}, \boldsymbol{G}$, and $\boldsymbol{H}$. Note the patches of autofluorescence in the paranodal myelin sheath, which were often observed. The origin of this autofluorescence is unclear, but it was present before activation $(\boldsymbol{F})$ and did not interfere with our analyses because it was located outside of the axon. Scale bar, $10 \mu \mathrm{m}$.

Thus, the nerves remained viable on the microscope stage for at least $3 \mathrm{~h}$ postmortem. A similar finding has been reported using bright-field imaging of organelle movement in axons of rat sciatic nerve (Viancour and Kreiter, 1993).

\section{Pulse-escape experiments}

Illumination of the tibial nerve axons from adult Thyl-paGFPNFM transgenic mice with violet light always resulted in photoactivation of paGFP-NFM fluorescence, indicating that the transgene was expressed ubiquitously in the neurons that form the superficial large myelinated axons in this nerve. Single neurofilaments could not be detected due the high neurofilament packing density (filaments spaced tens of nanometers apart, well below the diffraction limit) as well as the low expression level of the transgene. However, the high neurofilament content of these axons permitted a strong photoactivated signal overall.

Because the extent of nodal constriction (i.e., the ratio of internodal to nodal cross-sectional area) increases with increasing 

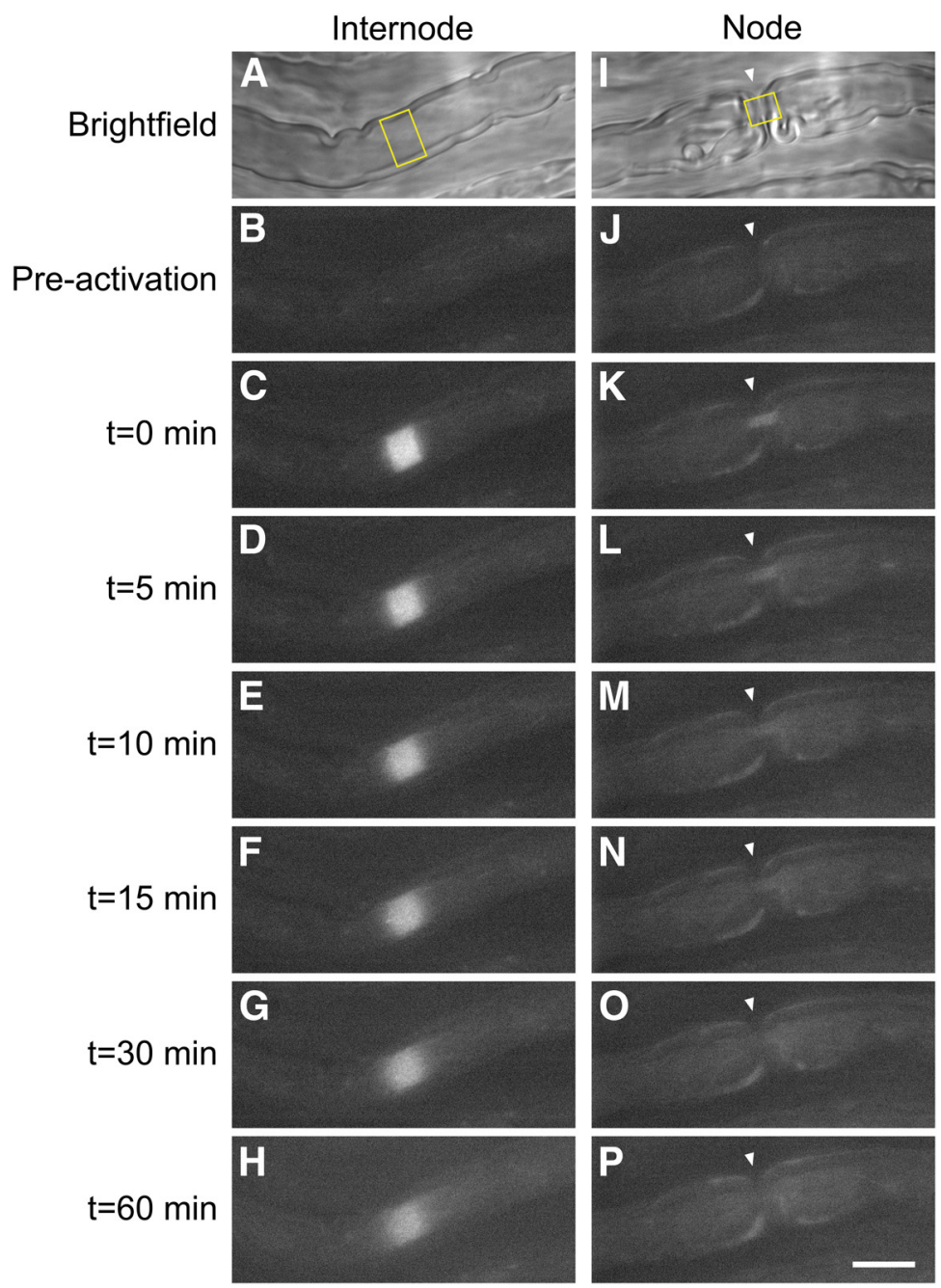

Figure 7. A pulse-escape experiment in a contiguous node and internode. $\boldsymbol{A}-\boldsymbol{H}$, An internode. $\boldsymbol{I}-\boldsymbol{P}$, Node of Ranvier. $\boldsymbol{A}, \boldsymbol{I}$, Bright-field images. Yellow region represents area that was activated. $\boldsymbol{B}, \boldsymbol{J}$, Images of the paGFP fluorescence before photoactivation. $\boldsymbol{C}, \boldsymbol{K}$, Images of the paGFP fluorescence immediately after activation. $\boldsymbol{D}-\boldsymbol{H}, \boldsymbol{L}-\boldsymbol{P}$, Images acquired at intervals of $5,10,15,30$, and $60 \mathrm{~min}$ after photoactivation. White arrowheads indicate the node of Ranvier. The images were acquired using identical illumination and exposure settings and the fluorescence intensities were scaled identically to allow direct comparison of the fluorescence intensities; the node appears relatively faint because it has a lower neurofilament content. The proximal and distal ends of the nodal and internodal activated regions become blurred over time due to the anterograde and retrograde movement of the fluorescent filaments. The fluorescence in the nodes dispersed more rapidly than in the internodes. Scale bar, $10 \mu \mathrm{m}$.

internodal caliber (Rydmark, 1981; Swärd et al., 1995), we selected only the largest axons ( $>3 \mu \mathrm{m}$ in internodal diameter) for the present study. Previous studies have shown that neurofilaments occupy most of the volume of myelinated axons, with their number increasing in proportion to axonal cross-sectional area (Friede and Samorajski, 1970). An axon with an internodal diameter of $6 \mu \mathrm{m}$ contains $\sim 5000$ neurofilaments in cross-section (Reles and Friede, 1991; Elder et al., 1999). Thus, activation of the neurofilament fluorescence made the entire axon fluorescent and revealed the axonal shape. In internodal regions, the axons were fairly uniform in diameter (Fig. 6A-D), narrowing slightly at regions of compression, such as Schwann cell nuclei and Schmidt-Lanterman clefts (Price et al., 1990). In contrast, at nodes of Ranvier, the axons expanded slightly in the juxtaparanodal regions and then narrowed abruptly in the paranodes, resulting in a marked reduction of axonal cross-sectional area within the nodal and flanking paranodal regions (Fig. $6 E-H$ ).

To compare the axonal transport of neurofilaments in nodes and internodes, we used the fluorescence photoactivation pulse- escape technique, which we developed previously to study neurofilament transport in cultured nerve cells (Trivedi et al., 2007; Alami et al., 2009; Li et al., 2014; Monsma et al., 2014). This is a population-based approach in which photoactivation is used to mark the axonal neurofilaments in a short segment of axon and then the transport kinetics of the fluorescent filaments are determined by computational modeling of the kinetics of their departure from the activated region (Li et al., 2014). To apply this method for the current study, we located nodes of Ranvier of large myelinated axons (internodal diameter $>3 \mu \mathrm{m}$ ) under bright-field illumination. For each axon, we first photoactivated the neurofilaments in the node (length of activated region $=5.5 \mu \mathrm{m})$ and tracked the loss of fluorescence by acquiring images at intervals over a period of 30 or $60 \mathrm{~min}$. We then moved several FOVs into a flanking internode along the same axon and repeated this analysis there using the same approach. Thus, the kinetics in each node could be compared with a contiguous internode along the same axon. For simplicity, we refer to the constricted region of the axon as the node, although technically it includes both the node and flanking paranodal regions (Fig. 1).

Figure 7 shows images from a pulseescape experiment. The intensities of the images were scaled identically to permit comparison between the node and internode. The intensity and width of the activated region immediately after activation $(t=0)$ were much greater in the internode than in the node because internodes contain many more neurofilaments and have a much larger axon diameter. Over time, the proximal and distal edges of the activated regions blurred and the intensity of the activated regions decreased due to the intermittent bidirectional movement of the fluorescent neurofilaments, as we have observed previously for myelinated axons in cell culture (Monsma et al., 2014). After $60 \mathrm{~min}$, the proportion of the fluorescence that remained in the nodes appeared to be less than in the flanking internodes (compare Fig. $7 H, P$ ).

Figure 8 shows the results of our quantitative analysis of the pulse-escape kinetics in contiguous nodes and internodes of 10 axons. There was considerable variation in the kinetics from one axon to another, which may reflect the heterogeneity of the axons in these mixed nerves. However, in every case, the fluorescence declined faster in the node than in the corresponding contiguous internode (e.g., Fig. $8 A-D$ ). As reported previously, the kinetics were biphasic and could be approximated by a doubleexponential decay function (Trivedi et al., 2007; Li et al., 2014). On average, the initial slope of the decay was approximately eightfold greater in the node than the internode, and the proportion of the fluorescence that had departed the activated region 

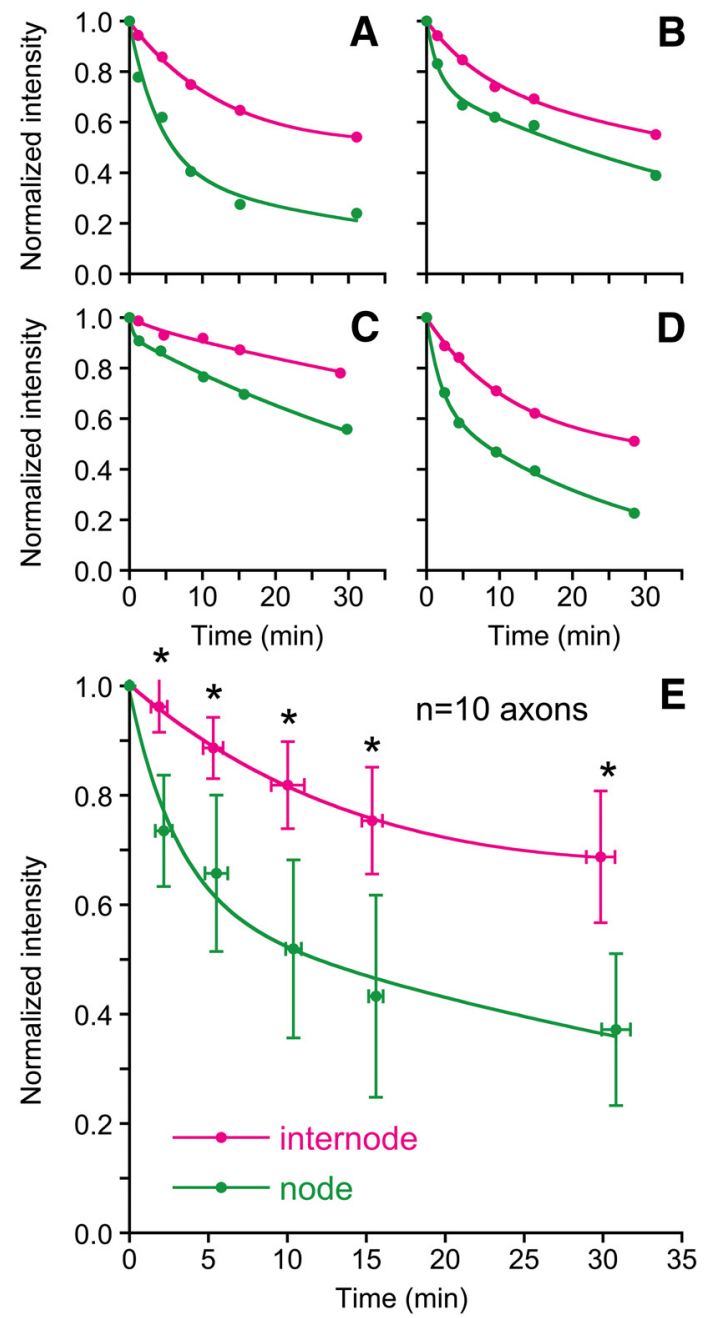

Figure 8. Pulse-escape kinetics in contiguous nodes and internodes. $A-D$, Examples of the pulse-escape kinetics for contiguous nodes (green) and internodes (magenta) along 4 different axons. The fluorescence intensity on the $y$ axis is normalized to the intensity immediately after photoactivation. $E$, Average decay kinetics for contiguous nodes and internodes along 10 axons. *Statistically significant difference $(p=0.0002$ at $t=2.5 \mathrm{~min}, p=0.001$ at $t=5 \mathrm{~min}, p=0.0001$ at $t=10 \mathrm{~min}, p=0.00008$ at $t=15 \mathrm{~min}, p=0.00007$ at $t=30 \mathrm{~min}$; two-tailed paired $t$ test). The lines on each graph are double-exponential curve fits of the form $y=a e^{-b x}+c e^{-d x}$.

after 30 min was $\sim 2$-fold greater (Fig. $8 E$ ). This indicates that, on average, the neurofilaments were more mobile in the nodes than in the flanking internodes. As we have shown in cultured neurons, there was no loss of fluorescence in nerves that were exposed to inhibitors of glycolysis (Fig. 9). This confirms that the loss of fluorescence from the activated regions was an active transport process and that there was no contribution of diffusion to the pulse-escape kinetics (Trivedi et al., 2007; Monsma et al., 2014).

\section{Morphometric analysis}

Because neurofilaments are distributed throughout large myelinated axons, the images of the photoactivated fluorescence can be used to measure the axon morphology. Figure 10 shows the morphometric data for the axons analyzed using the pulse-escape method in Figure 8. The average length of the nodal constrictions, which included the node and flanking paranodes, was $7.2 \mu \mathrm{m}$ (minimum $=5.9 \mu \mathrm{m}$, maximum $=8.6 \mu \mathrm{m}, n=10$; data not shown). The internodal diameter of the axons ranged from 3.5 to $6.1 \mu \mathrm{m}$ (average $=4.4 \mu \mathrm{m}, n=10)$, and the nodal diameter

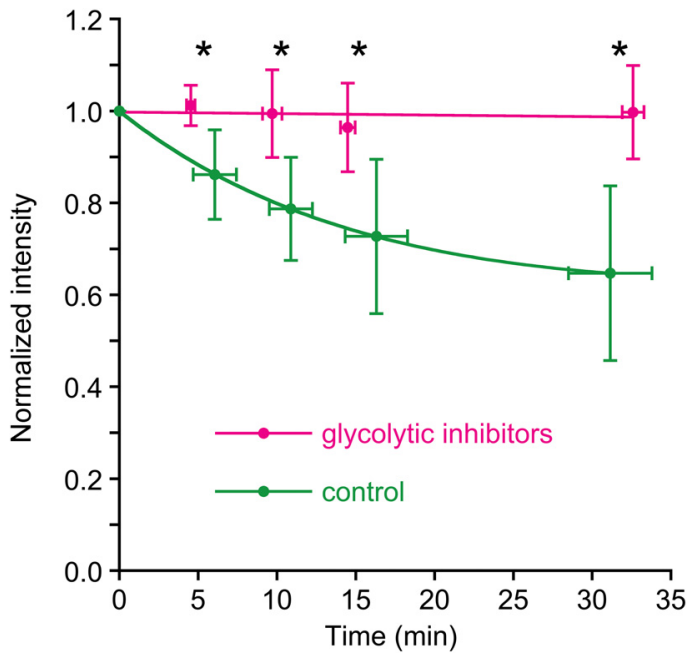

Figure 9. Inhibition of glycolysis blocks neurofilament transport. Average pulse-escape kinetics of nerves that were dissected and imaged in the presence or absence of glycolytic inhibitors (5.6 mm deoxyglucose and $0.5 \mathrm{~mm}$ iodoacetate), as described in Materials and Methods. The nerves were exposed to the inhibitors for $20-30 \mathrm{~min}$ before the start of the pulse-escape experiment. Bright-field microscopy confirmed the slowing or cessation of organelle movement in the nerves by this time. The control data (green) are the average of 8 axons from 4 different animals, and the test data (magenta) are the average of 5 axons from 3 different animals. *Statistically significant difference ( $p=0.003$ at $t=5 \mathrm{~min}, p=0.005$ at $t=10 \mathrm{~min}, p=0.008$ at $t=15 \mathrm{~min}, p=0.001$ at $t=30 \mathrm{~min}$; two-tailed $t$ test for samples with unequal variances). The lines on each graph are double-exponential curve fits of the form $y=a e^{-b x}+c e^{-d x}$.

ranged from 1.3 to $2.3 \mu \mathrm{m}$ (average $=1.7 \mu \mathrm{m}, n=10)$. Assuming a circular cross-section, this corresponded to a 6.4-fold decrease in average axonal cross-sectional area, from 15.7 to $2.5 \mu \mathrm{m}^{2}$. In comparison, the average intensity of the paGFP fluorescence decreased from 2298 to 304 (arbitrary fluorescence units). Assuming that the paGFP fluorescence is proportional to neurofilament number, this corresponds to a 7.6-fold decrease in neurofilament content (Fig. 10C). The axons were enlarged in the juxtaparanodal regions proximal and distal to each node (Fig. 10A), but this enlargement was not accompanied by an increase in neurofilament content (Fig. 10C). This juxtaparanodal enlargement is a characteristic feature of myelinated axons (Lubinska, 1954) and appears to be caused by the accumulation of membranous organelles proximal and distal to the nodes (Armstrong et al., 1987; Berthold et al., 1993; Fabricius et al., 1993).

\section{Kinetic analysis}

Neurofilament transport across a node of Ranvier may be considered analogous to fluid flow within a tube. In fluid dynamics, flow is governed by the Continuity Equation, which states that the mass of a fluid must be conserved across a local narrowing, resulting in an increase in the rate of flow. Thus, if we define the neurofilament content in the node and internode as $c_{\text {node }}$ and $c_{\text {internode }}$, then the ratio of the neurofilament velocities in the node and internode is constrained by $v_{\text {node }} / v_{\text {internode }}=c_{\text {internode }} / c_{\text {node }}$. For the myelinated axons analyzed in the pulse-escape photoactivation experiments above, this is given by the ratio of the average fluorescence intensities measured immediately after photoactivation (i.e., $c_{\text {internode }} / c_{\text {node }}=7.6$ ) (Fig. 10C).

We previously derived a mathematical description of the pulse-escape decay kinetics in terms of a 6-state kinetic model of neurofilament transport, allowing us to extract kinetic parameters of neurofilament transport from pulse-escape experiments (Li et al., 2014). Here, we used this approach to analyze the neu- 

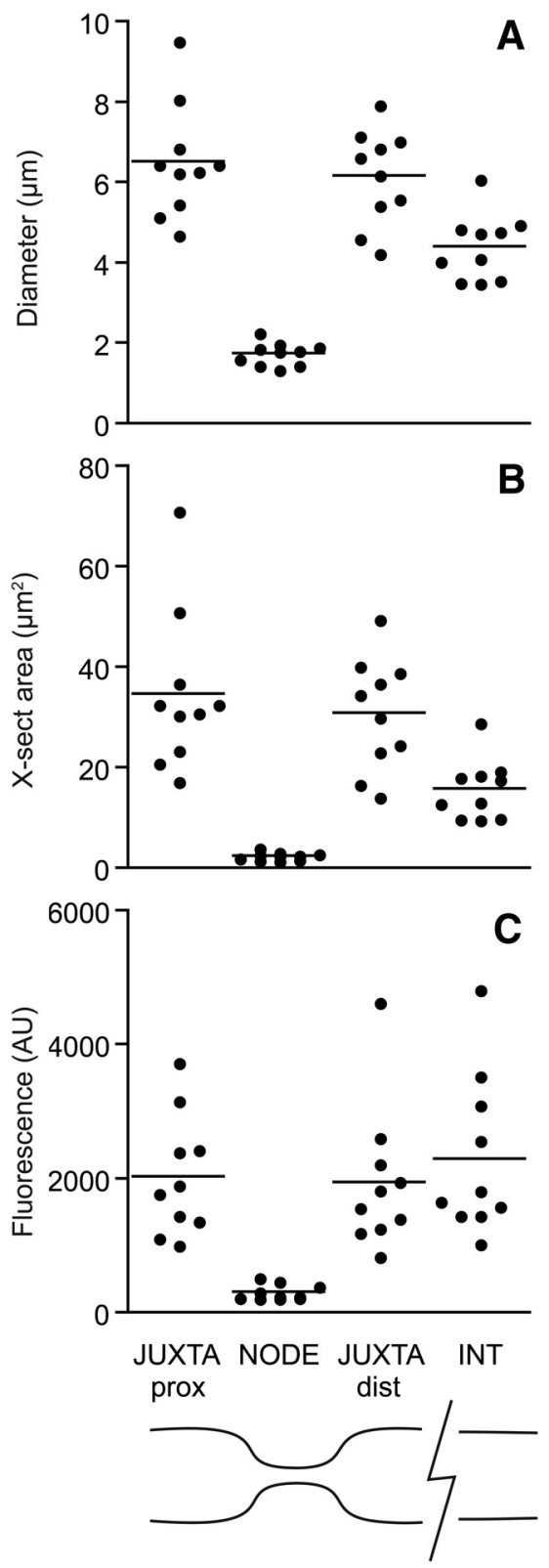

Figure 10. Morphometric analysis. Morphometric data for the nodes, internodes, and proximal and distal juxtaparanodes of the 10 axons analyzed using the pulse-escape method in Figure 8. $\boldsymbol{A}$, Average axon diameter. $\boldsymbol{B}$, Average axon cross-sectional area calculated from the diameter assuming a cylindrical shape. $\boldsymbol{C}$, Average fluorescence intensity immediately after photoactivation, which is a measure of the relative neurofilament content. On average, the axons were constricted 6.4-fold in the nodes and exhibited a 7.6-fold decrease in neurofilament content.

rofilament transport kinetics in nodes and internodes. We simulated pulse-escape experiments with $5.5 \mu \mathrm{m}$ activation windows and systematically varied the kinetic parameters $\gamma_{01}, \gamma_{10}, \gamma_{\text {off }}$ and $\gamma_{\text {on }}$, as described in Materials and Methods, to find the best match of the model-based simulations to the average pulseescape kinetics in Figure $8 E$, constrained by $v_{\text {node }} / v_{\text {internode }}=$ $c_{\text {internode }} / c_{\text {node }}=7.6$. Figure $11 \mathrm{~A}$ shows the resulting best fits of the model to the experimental data, Figure $11 B$ depicts the states and rate constants of the model, Figure $11 C$ shows the estimated values of the kinetic rate constants, and Figure $11 D$ shows the average pause times, percent time pausing, and velocities calculated from these rate constants (Li et al., 2014). The calculations suggest that the nodal neurofilaments spent more than twice their time on track ( $47 \%$ on track in nodes, $23 \%$ in internodes), with a 7.6-fold increase in the proportion of the time that they spent moving (3.6\% in nodes, $0.47 \%$ in internodes) despite a $47 \%$ increase in the average duration of the on-track pauses, $T_{\text {on }}(2.2 \mathrm{~min}$ in nodes, $1.5 \mathrm{~min}$ in internodes). Comparison of the calculated average pause times suggests that this change was due largely to a $36 \%$ decrease in the average duration of the off-track pauses, $T_{\text {off }}$ (61 min in nodes, $95 \mathrm{~min}$ in internodes), which is the dominant kinetic state for neurofilaments, and a 5.5-fold increase in the average run time (11 s in nodes, $2 \mathrm{~s}$ in internodes). Thus, neurofilaments spend more time engaged with their microtubule tracks in nodes, with longer (i.e., more persistent) runs and shorter off-track pauses.

Because neurofilament transport is bidirectional, the net velocity is dependent on the balance of anterograde and retrograde movements, which is governed by the ratio of the reversal rate constants in our model, specifically $\left(1-q_{3}\right) /\left(1+q_{3}\right)$, where $q_{3}=$ $\gamma_{\mathrm{ar}} / \gamma_{\mathrm{ra}}$ (Eq. 4). The reversal rates $\gamma_{\mathrm{ar}}$ and $\gamma_{\mathrm{ra}}$ cannot be determined from our pulse-escape kinetics because measurements of the loss of fluorescence are blind to the direction of neurofilament departure (Li et al., 2014). Thus, we cannot determine the net transport velocity in the node and internode, only the ratio of the velocities in these two domains. However, we have previously estimated the reversal rate constants in mouse sciatic nerve to be $\gamma_{\mathrm{ar}}=4.2 \times 10^{-6} \mathrm{~s}^{-1}$ and $\gamma_{\mathrm{ra}}=1.4 \times 10^{-5} \mathrm{~s}^{-1}$ based on computational modeling of radiosiotopic pulse labeling experiments (Jung and Brown, 2009). Assuming that these values also apply to tibial nerve, we calculate an average neurofilament transport velocity of $0.11 \mathrm{~mm} / \mathrm{d}$ in the internodes of tibial nerve axons, increasing to $0.83 \mathrm{~mm} / \mathrm{d}$ in the nodes. This estimate for the internodal neurofilament transport velocity is similar to experimental measurements of overall neurofilament transport velocity in distal sciatic nerve by radioisotopic pulse-labeling $(0.12$ $\mathrm{mm} / \mathrm{d}$ ) (Xu and Tung, 2001).

In summary, this analysis suggests that neurofilaments spend a large fraction $(99.5 \%)$ of their time pausing as they move through internodes, engaging in brief bouts of rapid movement interrupted by prolonged pauses. When they enter a node, the frequency and duration of these bouts of movement increase transiently, resulting in a higher average velocity.

\section{Discussion}

We described a novel Thyl-paGFP-NFM transgenic mouse line that permits analysis of neurofilament transport in mature adult myelinated axons. We used ex vivo imaging of tibial nerves from these mice to explore how neurofilaments navigate nodes of Ranvier, where local constriction of the axon presents a potential bottleneck for neurofilament transport. Our data indicate that neurofilaments navigate these nodal constrictions by accelerating transiently.

The notion that nodal constrictions represent bottlenecks for axonal transport was first proposed several decades ago (Okamura and Tsukita, 1986; Armstrong et al., 1987; Zimmermann, 1996). In support of this notion, live cell imaging studies on organelle movement in axons have revealed that large organelles frequently stall in juxtaparanodal regions (Cooper and Smith, 1974), and electron microscopic studies have revealed that axonally transported organelles tend to accumulate proximal and distal to nodes (Armstrong et al., 1987; Berthold et al., 1993; Fabricius et al., 1993). Because neurofilaments are also cargoes of axonal transport and occupy most of the axonal volume in large myelinated axons, any interruption in their transport would also 
be expected to cause them to accumulate and distort the axonal morphology. For example, when axons are constricted experimentally, neurofilaments pile up at the site of the constriction, leading to gross swelling of the axon (Le Beau et al., 1988; Koehnle and Brown, 1999). However, neurofilament accumulations are not observed adjacent to nodes in healthy axons. This conundrum was noted by Okamura and Tsukita (1986) and Reles and Friede (1991), who speculated that it could be explained if neurofilaments move faster through nodes or if they disassemble and reassemble reversibly on either side of nodes. Our present study provides experimental support for a local acceleration. We propose that this allows neurofilaments to navigate the narrow confines of nodal constrictions without accumulating in the juxtaparanodal regions, thereby ensuring that myelinated axons maintain a stable morphology across these physiologically important structures.

Several laboratories have performed live imaging of organelle movement using fluorescence microscopy of mouse peripheral nerves ex vivo (Misgeld et al., 2007; Zhang et al., 2010; Gilley et al., 2012; Marinkovic et al., 2012; Milde et al., 2015) and in vivo (Gibbs et al., 2016), but the present study represents the first imaging of slow axonal transport using this approach. Although we excised the nerve from the animal for the present study, the preparation remained vital for at least $3 \mathrm{~h}$. In future studies, the Thyl-paGFP-NFM mouse could also be used to image neurofilament transport in vivo. In principle, it is possible that the incorporation of the paGFP-NFM fluorescent fusion protein into the filaments could alter their transport kinetics, such as by altering their interactions with the transport machinery. This is a potential concern for all fluorescence imaging studies on neurofilament transport, including our studies in cultured neurons, but we believe that it is mitigated to a great extent in our present study by the very low expression level of the paGFP-NFM transgene in peripheral nerves, which we estimated to be $1.6 \%$ of the endogenous NFM protein. Thus, we believe that the kinetics that we observed in our transgenic mice ex vivo should be a close approximation of the kinetics in WT mice in vivo.

Although nodal constrictions are important for neuronal function (Halter and Clark, 1993; Johnson et al., 2015), it is not clear how their morphology is generated and maintained. Mice lacking neurofilaments exhibit a 50\% reduction in average

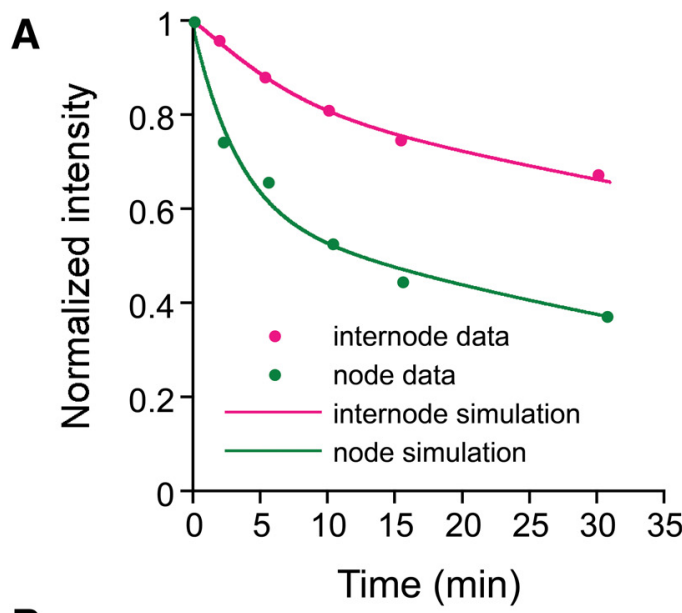

B

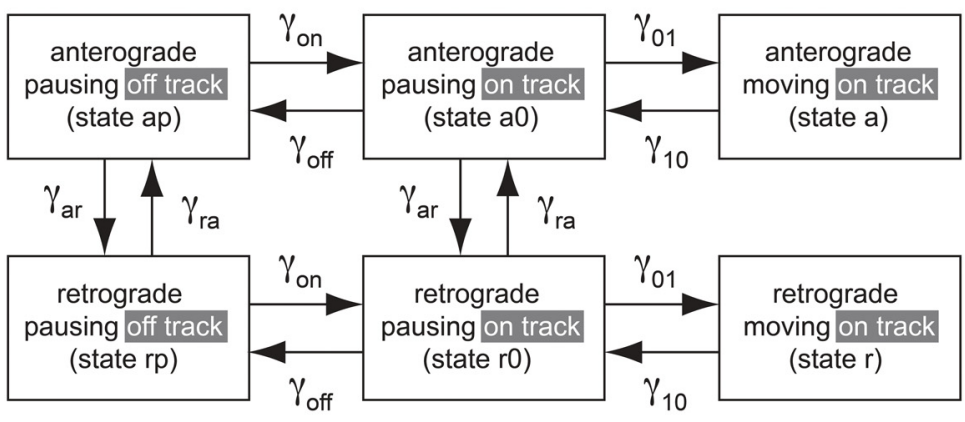

C

\begin{tabular}{|l|c|c|}
\hline Rate constant & Internode & Node \\
\hline$\gamma_{01}$ & $1.0 \times 10^{-2} \mathrm{~s}^{-1}$ & $7.4 \times 10^{-3} \mathrm{~s}^{-1}$ \\
\hline$\gamma_{10}$ & $4.9 \times 10^{-1} \mathrm{~s}^{-1}$ & $8.9 \times 10^{-2} \mathrm{~s}^{-1}$ \\
\hline$\gamma_{\text {on }}$ & $1.8 \times 10^{-4} \mathrm{~s}^{-1}$ & $2.8 \times 10^{-4} \mathrm{~s}^{-1}$ \\
\hline$\gamma_{\text {off }}$ & $6.0 \times 10^{-4} \mathrm{~s}^{-1}$ & $3.4 \times 10^{-4} \mathrm{~s}^{-1}$ \\
\hline
\end{tabular}

D

\begin{tabular}{|l|c|c|}
\hline Kinetic parameter & Internode & Node \\
\hline$\%$ on track $\rho_{\text {on }} \equiv \rho_{\mathrm{a}}+\rho_{\mathrm{r}}+\rho_{\mathrm{a} 0}+\rho_{\mathrm{r} 0}$ & $23 \%$ & $47 \%$ \\
\hline$\%$ off track $\rho_{\text {off }} \equiv \rho_{\mathrm{ap}}+\rho_{\mathrm{rp}}$ & $77 \%$ & $53 \%$ \\
\hline$\%$ moving $\rho_{\text {run }} \equiv \rho_{\mathrm{ap}}+\rho_{\mathrm{rp}}$ & $0.47 \%$ & $3.6 \%$ \\
\hline On-track pause $<T_{\text {on }}>=1 /\left(\gamma_{01}+\gamma_{\text {off }}\right)$ & $1.5 \mathrm{~min}$ & $2.2 \mathrm{~min}$ \\
\hline Off-track pause $<T_{\text {off }}>=1 / \gamma_{\text {on }}$ & $95 \mathrm{~min}$ & $61 \mathrm{~min}$ \\
\hline On-track move $<T_{\text {run }}>=1 /\left(\gamma_{10}\right)$ & $2 \mathrm{~s}$ & $11 \mathrm{~s}$ \\
\hline Velocity ratio $v_{\text {node }} / v_{\text {internode }}$ & \multicolumn{2}{|c|}{7.6} \\
\hline
\end{tabular}

Figure 11. Computational modeling of the pulse-escape kinetics. A, Average decay kinetics for contiguous nodes (green) and internodes (magenta) from Figure $8 E$. The curves represent the "best fit" to the model. $\boldsymbol{B}$, Schematic of the six-state model of neurofilament transport from Jung and Brown (2009), showing the rate constants that govern the transitions between the moving and pausing states. C, Table of the rate constants for the optimized simulations that are shown in $\boldsymbol{A}$. D, Table of the kinetic parameters calculated using the expressions in Materials and Methods (Eqs. 4, 7). The reversal rates $\gamma_{\mathrm{ar}}$ and $\gamma_{\mathrm{ra}}$ cannot be determined because measurements of the loss of fluorescence from the activation window are blind to the direction of neurofilament departure. 
axon caliber but still develop nodal constrictions (Perrot et al., 2007). Thus, the decrease in neurofilament number in nodes appears to be a consequence, not a cause, of nodal constrictions. Price et al. $(1990,1993)$ proposed that nodal constrictions result from local compression by the myelinating cells, and Zimmermann (1996) proposed that such forces could be generated by actomyosin-dependent contraction of the paranodal loops. Alternatively, nodal constrictions could be established and maintained by intrinsic forces exerted by the submembranous axonal cytoskeleton (Susuki et al., 2016).

Neurofilaments accumulate abnormally in the axons and/or cell bodies of neurons in many neurodegenerative and neurotoxic disorders, and this is thought to be caused by alterations in neurofilament transport (De Vos et al., 2008; Millecamps and Julien, 2013). Intriguingly, studies on rodent models have revealed that these accumulations often appear proximal to nodes of Ranvier (e.g., Griffin et al., 1982; Jones and Cavanagh, 1983; Jacobs, 1984; Gold et al., 1986; Hirai et al., 1999; Lancaster et al., 2018). This suggests that nodal bottlenecks may be particularly vulnerable sites for neurofilament accumulation in disease. Our present data suggest that such accumulations could arise due to a defect in the mechanisms that accelerate neurofilaments in nodal constrictions.

While not the focus of this study, two additional features of our data are worth noting. First, our modeling predicts that neurofilaments in nodes and internodes pause on average $96.4 \%$ and $99.5 \%$ of the time, respectively. Thus, pausing dominates the transport behavior of neurofilaments in these axons, even in nodes. This is consistent with our computational modeling of radioisotopic pulse-labeling and pulse-escape experiments, which have predicted that neurofilaments spend $95 \%-99 \%$ of their time pausing in motor axons of distal mouse sciatic nerve and in internodes of myelinated axons in culture (Brown et al., 2005; Craciun et al., 2005; Jung and Brown, 2009; Li et al., 2012; Monsma et al., 2014). The dominance of pausing in the axonal transport of neurofilaments explains the slow average rate of movement of these cargoes (Brown, 2000, 2003). Nonetheless, it is remarkable how dynamic the neurofilament array is. For example, on average $60 \%$ of the fluorescent filaments had departed the nodal activated regions in only $30 \mathrm{~min}$ in our experiments, and our computational analysis predicted an average off-track pause time of $\left\langle T_{\text {off }}\right\rangle=61 \mathrm{~min}$ in nodes and $\left\langle T_{\text {off }}\right\rangle=95 \mathrm{~min}$ in internodes. Thus, while the filaments spend most of their time pausing, they are continually cycling between the moving and pausing states with average pause times on the order of $1-2 \mathrm{~h}$.

A second notable feature of our data is that the neurofilament transport exhibited no obvious directional bias. In the movies, this was manifested as an approximately symmetrical blurring of the activated regions in both anterograde and retrograde directions, as we have reported previously for myelinated axons in cell culture (Monsma et al., 2014). This is consistent with experimental evidence that neurofilament transport is bidirectional in cultured neurons (Wang et al., 2000; Uchida and Brown, 2004; Uchida et al., 2009) and also in vivo (Glass and Griffin, 1991, 1994; Watson et al., 1993), as well as with prior computational modeling of radioisotopic pulse-labeling experiments, which suggested that the filaments spent $\sim 45 \%$ of their time moving retrogradely in distal motor axons of adult mice (Brown et al., 2005; Jung and Brown, 2009).

Although we have not yet performed fine-scale kinetic mapping across nodal constrictions, the abrupt transition in neurofilament number in the juxtaparanodal regions implies that there are equally abrupt transitions in neurofilament transport kinetics. Little is pres- ently known about the regulation of neurofilament transport. There is evidence that neurofilament phosphorylation correlates with a slowing of neurofilament transport in vivo (Archer et al., 1994; Nixon et al., 1994; Toyoshima and Komiya, 1995; Sánchez et al., 1996, 2000; Jung et al., 2000) and that phosphorylation slows neurofilament transport in cultured neurons by increasing neurofilament pausing (Ackerley et al., 2000, 2003). There is also one report that phosphoepitopes on neurofilaments are reduced at nodes of Ranvier (Mata et al., 1992). Thus, the acceleration of neurofilaments in nodes could be caused by signaling mechanisms that transiently dephosphorylate neurofilaments. For example, it is possible that neurofilament dephosphorylation in nodes could increase the affinity of these polymers for their motors, resulting in longer runs and shorter pauses. However, because neurofilament phosphorylation also influences the spacefilling properties of these polymers (Mukhopadhyay et al., 2004) and because neurofilaments tend to be spaced closer together in nodes (Price et al., 1988; Hsieh et al., 1994), it is also possible that this decrease in phosphorylation reflects the increased neurofilament packing density and is unrelated to their transport behavior. To complicate things further, a decrease in neurofilament phosphorylation has also been reported in locally demyelinated axons, but in that study it was associated with a slowing of neurofilament transport, not an acceleration (de Waegh et al., 1992).

A second possible mechanism for the nodal acceleration of neurofilaments is that it is a simple consequence of the proximity of the neurofilaments to their microtubule tracks. Like any cargo, neurofilaments can only move if they are adjacent to a track. In internodes of large myelinated axons, neurofilaments greatly outnumber microtubules (Friede and Samorajski, 1970; Price et al., 1988; Reles and Friede, 1991); consequently, many internodal neurofilaments are not adjacent to a microtubule. However, the fact that there is no reduction in microtubule number in nodes (Tsukita and Ishikawa, 1981; Reles and Friede, 1991; Hsieh et al., 1994) (Fig. 1) means that the neurofilament-to-microtubule ratio decreases locally in nodes, as does the average distance between neurofilaments and their microtubule tracks. This effect could be compounded by the increased neurofilament packing density in nodes. Collectively, these organizational changes in the cytoskeleton may have the effect of increasing the probability that neurofilaments interact with their tracks, decreasing the average pause time and increasing the average velocity of neurofilament transport in nodal constrictions. According to this model, the continuity of microtubules across nodes of Ranvier may be critical to ensure that neurofilaments can navigate these axonal bottlenecks.

\section{References}

Ackerley S, Grierson AJ, Brownlees J, Thornhill P, Anderton BH, Leigh PN, Shaw CE, Miller CC (2000) Glutamate slows axonal transport of neurofilaments in transfected neurons. J Cell Biol 150:165-176. CrossRef Medline

Ackerley S, Thornhill P, Grierson AJ, Brownlees J, Anderton BH, Leigh PN, Shaw CE, Miller CC (2003) Neurofilament heavy chain side arm phosphorylation regulates axonal transport of neurofilaments. J Cell Biol 161: 489-495. CrossRef Medline

Alami NH, Jung P, Brown A (2009) Myosin va increases the efficiency of neurofilament transport by decreasing the duration of long-term pauses. J Neurosci 29:6625-6634. CrossRef Medline

Archer DR, Watson DF, Griffin JW (1994) Phosphorylation-dependent immunoreactivity of neurofilaments and the rate of slow axonal transport in the central and peripheral axons of the rat dorsal root ganglion. J Neurochem 62:1119-1125. CrossRef Medline

Armstrong R, Toews AD, Morell P (1987) Axonal transport through nodes of Ranvier. Brain Res 412:196-199. CrossRef Medline 
Beaulieu JM, Nguyen MD, Julien JP (1999) Late onset death of motor neurons in mice overexpressing wild-type peripherin. J Cell Biol 147:531544. CrossRef Medline

Berthold CH (1978) Morphology of normal peripheral nerve axons. In: Physiology and pathobiology of axons (Waxman SG, ed). New York: Raven.

Berthold CH (1996) Development of nodes of Ranvier in feline nerves: an ultrastructural presentation. Microsc Res Tech 34:399-421. CrossRef Medline

Berthold CH, Fabricius C, Rydmark M, Andersén B (1993) Axoplasmic organelles at nodes of Ranvier: I. Occurrence and distribution in large myelinated spinal root axons of the adult cat. J Neurocytol 22:925-940. CrossRef Medline

Bloom OE, Morgan JR (2011) Membrane trafficking events underlying axon repair, growth, and regeneration. Mol Cell Neurosci 48:339-348. CrossRef Medline

Breuer AC, Lynn MP, Atkinson MB, Chou SM, Wilbourn AJ, Marks KE, Culver JE, Fleegler EJ (1987) Fast axonal transport in amyotrophic lateral sclerosis: an intra-axonal organelle traffic analysis. Neurology 37: 738-748. CrossRef Medline

Brinster RL, Chen HY, Trumbauer M, Senear AW, Warren R, Palmiter RD (1981) Somatic expression of herpes thymidine kinase in mice following injection of a fusion gene into eggs. Cell 27:223-231. CrossRef Medline

Brown A (2000) Slow axonal transport: stop and go traffic in the axon. Nat Rev Mol Cell Biol 1:153-156. CrossRef Medline

Brown A (2003) Axonal transport of membranous and nonmembranous cargoes: a unified perspective. J Cell Biol 160:817-821. CrossRef Medline

Brown A (2014) Slow axonal transport. In: Reference module in the biomedical sciences (Caplan M, ed). Amsterdam: Elsevier.

Brown A, Wang L, Jung P (2005) Stochastic simulation of neurofilament transport in axons: the "stop-and-go" hypothesis. Mol Biol Cell 16:42434255. CrossRef Medline

Chang KJ, Rasband MN (2013) Excitable domains of myelinated nerves: axon initial segments and nodes of Ranvier. Curr Top Membr 72:159192. CrossRef Medline

Cooper PD, Smith RS (1974) The movement of optically detectable organelles in myelinated axons of Xenopus laevis. J Physiol 242:77-97. CrossRef Medline

Craciun G, Brown A, Friedman A (2005) A dynamical system model of neurofilament transport in axons. J Theor Biol 237:316-322. CrossRef Medline

De Vos KJ, Grierson AJ, Ackerley S, Miller CC (2008) Role of axonal transport in neurodegenerative diseases. Annu Rev Neurosci 31:151-173. CrossRef Medline

de Waegh SM, Lee VM, Brady ST (1992) Local modulation of neurofilament phosphorylation, axonal caliber, and slow axonal transport by myelinating Schwann cells. Cell 68:451-463. CrossRef Medline

Elder GA, Friedrich VL Jr, Margita A, Lazzarini RA (1999) Age-related atrophy of motor axons in mice deficient in the mid-sized neurofilament subunit. J Cell Biol 146:181-192. CrossRef Medline

Fabricius C, Berthold CH, Rydmark M (1993) Axoplasmic organelles at nodes of Ranvier: II. Occurrence and distribution in large myelinated spinal cord axons of the adult cat. J Neurocytol 22:941-954. CrossRef Medline

Friede RL, Samorajski T (1970) Axon caliber related to neurofilaments and microtubules in sciatic nerve fibers of rats and mice. Anat Rec 167:379387. CrossRef Medline

Friede RL, Miyaghishi T, Hu KH (1971) Axon calibre, neurofilaments, microtubules, sheath thickness and cholesterol in cat optic nerve fibres. J Anat 108:365-373. Medline

Gibbs KL, Kalmar B, Sleigh JN, Greensmith L, Schiavo G (2016) In vivo imaging of axonal transport in murine motor and sensory neurons. J Neurosci Methods 257:26-33. CrossRef Medline

Gilley J, Seereeram A, Ando K, Mosely S, Andrews S, Kerschensteiner M, Misgeld T, Brion JP, Anderton B, Hanger DP, Coleman MP (2012) Agedependent axonal transport and locomotor changes and tau hypophosphorylation in a "P301L" tau knockin mouse. Neurobiol Aging 33: 621.e1-621.e15. CrossRef Medline

Glass JD, Griffin JW (1991) Neurofilament redistribution in transected nerves: evidence for bidirectional transport of neurofilaments. J Neurosci 11:3146-3154. CrossRef Medline

Glass JD, Griffin JW (1994) Retrograde transport of radiolabeled cytoskel- etal proteins in transected nerves. J Neurosci 14:3915-3921. CrossRef Medline

Gold BG, Griffin JW, Price DL, Cork LC, Lowndes HE (1986) Structural correlates of physiological abnormalities in beta, beta'-iminodipropionitrile. Brain Res 362:205-213. CrossRef Medline

Griffin JW, Gold BG, Cork LC, Price DL, Lowndes HE (1982) IDPN neuropathy in the cat: coexistence of proximal and distal axonal swellings. Neuropathol Appl Neurobiol 8:351-364. CrossRef Medline

Halter JA, Clark JW Jr (1993) The influence of nodal constriction on conduction velocity in myelinated nerve fibers. Neuroreport 4:89-92. CrossRef Medline

Hess A, Young JZ (1952) The nodes of Ranvier. Proc R Soc Lond B Biol Sci 140:301-320. CrossRef Medline

Hildebrand C (1971) Ultrastructural and light-microscopic studies of the nodal region in large myelinated fibres of the adult feline spinal cord white matter. Acta Physiol Scand Suppl 364:43-79. Medline

Hildebrand C, Remahl S, Persson H, Bjartmar C (1993) Myelinated nerve fibres in the CNS. Prog Neurobiol 40:319-384. CrossRef Medline

Hirai T, Mizutani M, Kimura T, Ochiai K, Umemura T, Itakura C (1999) Neurotoxic effects of 2,5-hexanedione on normal and neurofilamentdeficient quail. Toxicol Pathol 27:348-353. CrossRef Medline

Hoffman PN (1995) The synthesis, axonal transport, and phosphorylation of neurofilaments determine axonal caliber in myelinated nerve fibers. Neuroscientist 1:76-83. CrossRef

Hoffman PN, Lasek RJ (1975) The slow component of axonal transport: identification of major structural polypeptides of the axon and their generality among mammalian neurons. J Cell Biol 66:351-366. CrossRef Medline

Hsieh ST, Kidd GJ, Crawford TO, Xu Z, Lin WM, Trapp BD, Cleveland DW, Griffin JW (1994) Regional modulation of neurofilament organization by myelination in normal axons. J Neurosci 14:6392-6401. CrossRef Medline

Jacobs JM (1984) Toxic effects on the node of Ranvier. In: The node of Ranvier (Zagoren J, ed), pp 245-272. San Diego: Academic.

Johnson C, Holmes WR, Brown A, Jung P (2015) Minimizing the caliber of myelinated axons by means of nodal constrictions. J Neurophysiol 114: 1874-1884. CrossRef Medline

Jones HB, Cavanagh JB (1983) Distortions of nodes of Ranvier from axonal distension by filamentous masses in hexacarbon intoxication. J Neurocytol 12:439-458. CrossRef Medline

Jung C, Yabe JT, Shea TB (2000) C-terminal phosphorylation of the high molecular weight neurofilament subunit correlates with decreased neurofilament axonal transport velocity. Brain Res 856:12-19. CrossRef Medline

Jung P, Brown A (2009) Modeling the slowing of neurofilament transport along the mouse sciatic nerve. Phys Biol 6:046002. CrossRef Medline

Koehnle TJ, Brown A (1999) Slow axonal transport of neurofilament protein in cultured neurons. J Cell Biol 144:447-458. CrossRef Medline

Lancaster E, Li J, Hanania T, Liem R, Scheideler MA, Scherer SS (2018) Myelinated axons fail to develop properly in a genetically authentic mouse model of Charcot-Marie-Tooth disease type 2E. Exp Neurol 308:13-25. CrossRef Medline

Lasek RJ, Paggi P, Katz MJ (1992) Slow axonal transport mechanisms move neurofilaments relentlessly in mouse optic axons. J Cell Biol 117:607-616. CrossRef Medline

Lasek RJ, Paggi P, Katz MJ (1993) The maximum rate of neurofilament transport in axons: a view of molecular transport mechanisms continuously engaged. Brain Res 616:58-64. CrossRef Medline

Le Beau JM, Ellisman MH, Powell HC (1988) Ultrastructural and morphometric analysis of long term peripheral nerve regeneration through silicone tubes. J Neurocytol 17:161-172. CrossRef Medline

Li Y, Jung P, Brown A (2012) Axonal transport of neurofilaments: a single population of intermittently moving polymers. J Neurosci 32:746-758. CrossRef Medline

Li Y, Brown A, Jung P (2014) Deciphering the axonal transport kinetics of neurofilaments using the fluorescence photoactivation pulse-escape method. Phys Biol 11:026001. CrossRef Medline

Lubinska L (1954) Form of myelinated nerve fibres. Nature 173:867-869. CrossRef Medline

Mar FM, Simões AR, Leite S, Morgado MM, Santos TE, Rodrigo IS, Teixeira CA, Misgeld T, Sousa MM (2014) CNS axons globally increase ax- 
onal transport after peripheral conditioning. J Neurosci 34:59655970. CrossRef Medline

Marinkovic P, Reuter MS, Brill MS, Godinho L, Kerschensteiner M, Misgeld $\mathrm{T}$ (2012) Axonal transport deficits and degeneration can evolve independently in mouse models of amyotrophic lateral sclerosis. Proc Natl Acad Sci U S A 109:4296-4301. CrossRef Medline

Mata M, Kupina N, Fink DJ (1992) Phosphorylation-dependent neurofilament epitopes are reduced at the node of Ranvier. J Neurocytol 21:199210. CrossRef Medline

Milde S, Adalbert R, Elaman MH, Coleman MP (2015) Axonal transport declines with age in two distinct phases separated by a period of relative stability. Neurobiol Aging 36:971-981. CrossRef Medline

Millecamps S, Julien JP (2013) Axonal transport deficits and neurodegenerative diseases. Nat Rev Neurosci 14:161-176. CrossRef Medline

Misgeld T, Kerschensteiner M, Bareyre FM, Burgess RW, Lichtman JW (2007) Imaging axonal transport of mitochondria in vivo. Nat Methods 4:559-561. CrossRef Medline

Monsma PC, Li Y, Fenn JD, Jung P, Brown A (2014) Local regulation of neurofilament transport by myelinating cells. J Neurosci 34:2979-2988. CrossRef Medline

Mukhopadhyay R, Kumar S, Hoh JH (2004) Molecular mechanisms for organizing the neuronal cytoskeleton. Bioessays 26:1017-1025. CrossRef Medline

Nave KA, Werner HB (2014) Myelination of the nervous system: mechanisms and functions. Annu Rev Cell Dev Biol 30:503-533. CrossRef Medline

Nixon RA, Paskevich PA, Sihag RK, Thayer CY (1994) Phosphorylation on carboxyl terminus domains of neurofilament proteins in retinal ganglion cell neurons in vivo: influences on regional neurofilament accumulation, interneurofilament spacing, and axon caliber. J Cell Biol 126:1031-1046. CrossRef Medline

Okamura Y, Tsukita S (1986) Morphology of freeze-substituted myelinated axon in mouse peripheral nerves. Brain Res 383:146-158. CrossRef Medline

Patterson GH, Lippincott-Schwartz J (2002) A photoactivatable GFP for selective photolabeling of proteins and cells. Science 297:1873-1877. CrossRef Medline

Perrot R, Lonchampt P, Peterson AC, Eyer J (2007) Axonal neurofilaments control multiple fiber properties but do not influence structure or spacing of nodes of Ranvier. J Neurosci 27:9573-9584. CrossRef Medline

Price RL, Paggi P, Lasek RJ, Katz MJ (1988) Neurofilaments are spaced randomly in the radial dimension of axons. J Neurocytol 17:55-62. CrossRef Medline

Price RL, Lasek RJ, Katz MJ (1990) Internal axonal cytoarchitecture is shaped locally by external compressive forces. Brain Res 530:205-214. CrossRef Medline

Price RL, Lasek RJ, Katz MJ (1993) Neurofilaments assume a less random architecture at nodes and in other regions of axonal compression. Brain Res 607:125-133. CrossRef Medline

Reles A, Friede RL (1991) Axonal cytoskeleton at the nodes of Ranvier. J Neurocytol 20:450-458. CrossRef Medline

Rydmark M (1981) Nodal axon diameter correlates linearly with internodal axon diameter in spinal roots of the cat. Neurosci Lett 24:247-250. CrossRef Medline

Rydmark M, Berthold CH (1983) Electron microscopic serial section analysis of nodes of Ranvier in lumbar spinal roots of the cat: a morphometric study of nodal compartments in fibres of different sizes. J Neurocytol 12:537-565. CrossRef Medline

Salzer JL (2003) Polarized domains of myelinated axons. Neuron 40:297318. CrossRef Medline

Sánchez I, Hassinger L, Paskevich PA, Shine HD, Nixon RA (1996) Oligodendroglia regulate the regional expansion of axon caliber and local accumulation of neurofilaments during development independently of myelin formation. J Neurosci 16:5095-5105. CrossRef Medline

Sánchez I, Hassinger L, Sihag RK, Cleveland DW, Mohan P, Nixon RA (2000) Local control of neurofilament accumulation during radial growth of myelinating axons in vivo: selective role of site-specific phosphorylation. J Cell Biol 151:1013-1024. CrossRef Medline

Schindelin J, Arganda-Carreras I, Frise E, Kaynig V, Longair M, Pietzsch T, Preibisch S, Rueden C, Saalfeld S, Schmid B, Tinevez JY, White DJ,
Hartenstein V, Eliceiri K, Tomancak P, Cardona A (2012) Fiji: an opensource platform for biological-image analysis. Nat Methods 9:676-682. CrossRef Medline

Schmidt MM, Dringen R (2009) Differential effects of iodoacetamide and iodoacetate on glycolysis and glutathione metabolism of cultured astrocytes. Front Neuroenergetics 1:1-10. CrossRef Medline

Shelanski ML, Albert S, DeVries GH, Norton WT (1971) Isolation of filaments from brain. Science 174:1242-1245. CrossRef Medline

Smith RS (1989) Real-time imaging of axonally transported subresolution organelles in vertebrate myelinated axons. J Neurosci Methods 26:203209. CrossRef Medline

Smith RS, Bisby MA (1993) Persistence of axonal transport in isolated axons of the mouse. Eur J Neurosci 5:1127-1135. CrossRef Medline

Spaeth CS, Spaeth EB, Wilcott RW, Fan JD, Robison T, Bittner GD (2012) Pathways for plasmalemmal repair mediated by PKA, Epac, and cytosolic oxidation in rat B104 cells in vitro and rat sciatic axons ex vivo. Dev Neurobiol 72:1399-1414. CrossRef Medline

Susuki K, Otani Y, Rasband MN (2016) Submembranous cytoskeletons stabilize nodes of Ranvier. Exp Neurol 283:446-451. CrossRef Medline

Swärd C, Berthold CH, Nilsson-Remahl I, Rydmark M (1995) Axonal constriction at Ranvier's node increases during development. Neurosci Lett 190:159-162. CrossRef Medline

Toyoshima I, Komiya Y (1995) Phosphorylation and transport of neurofilament proteins in the rat spinal ganglion. Neurosci Lett 189:69-72. CrossRef Medline

Trivedi N, Jung P, Brown A (2007) Neurofilaments switch between distinct mobile and stationary states during their transport along axons. J Neurosci 27:507-516. CrossRef Medline

Tsukita S, Ishikawa H (1981) The cytoskeleton in myelinated axons: serial section study. Biomed Res 2:424-437. CrossRef Medline

Uchida A, Brown A (2004) Arrival, reversal and departure of neurofilaments at the tips of growing axons. Mol Biol Cell 15:4215-4225. CrossRef Medline

Uchida A, Komiya Y, Tashiro T, Yorifuji H, Kishimoto T, Nabeshima Y, Hisanaga S (2001) Neurofilaments of klotho, the mutant mouse prematurely displaying symptoms resembling human aging. J Neurosci Res 64 : 364-370. CrossRef Medline

Uchida A, Tashiro T, Komiya Y, Yorifuji H, Kishimoto T, Hisanaga S (2004) Morphological and biochemical changes of neurofilaments in aged rat sciatic nerve axons. J Neurochem 88:735-745. CrossRef Medline

Uchida A, Alami NH, Brown A (2009) Tight functional coupling of kinesin-1 A and dynein motors in the bidirectional transport of neurofilaments. Mol Biol Cell 20:4997-5006. CrossRef Medline

Viancour TA, Kreiter NA (1993) Vesicular fast axonal transport rates in young and old rat axons. Brain Res 628:209-217. CrossRef Medline

Vidal M, Morris R, Grosveld F, Spanopoulou E (1990) Tissue-specific control elements of the thy-1 gene. EMBO J 9:833-840. CrossRef Medline

Wang L, Brown A (2001) Rapid intermittent movement of axonal neurofilaments observed by fluorescence photobleaching. Mol Biol Cell 12: 3257-3267. CrossRef Medline

Wang L, Ho CL, Sun D, Liem RK, Brown A (2000) Rapid movement of axonal neurofilaments interrupted by prolonged pauses. Nat Cell Biol 2:137-141. CrossRef Medline

Watson DF, Glass JD, Griffin JW (1993) Redistribution of cytoskeletal proteins in mammalian axons disconnected from their cell bodies. J Neurosci 13:4354-4360. CrossRef Medline

Xia CH, Roberts EA, Her LS, Liu X, Williams DS, Cleveland DW, Goldstein LS (2003) Abnormal neurofilament transport caused by targeted disruption of neuronal kinesin heavy chain KIF5A. J Cell Biol 161:55-66. CrossRef Medline

Xu Z, Tung VW (2001) Temporal and spatial variations in slow axonal transport velocity along peripheral motoneuron axons. Neuroscience 102:193-200. CrossRef Medline

Zhang CL, Ho PL, Kintner DB, Sun D, Chiu SY (2010) Activity-dependent regulation of mitochondrial motility by calcium and $\mathrm{Na} / \mathrm{K}-\mathrm{ATPase}$ at nodes of Ranvier of myelinated nerves. J Neurosci 30:3555-3566. CrossRef Medline

Zimmermann H (1996) Accumulation of synaptic vesicle proteins and cytoskeletal specializations at the peripheral node of Ranvier. Microsc Res Tech 34:462-473. CrossRef Medline 